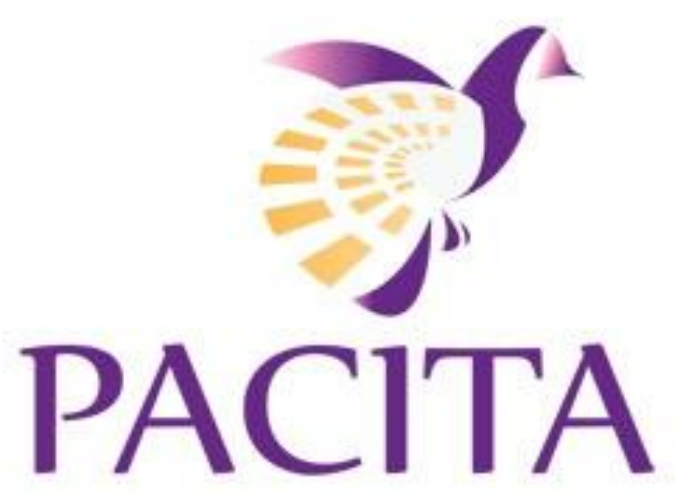

\title{
PACITA
}

Collaborative project on mobilisation and mutual learning actions in European Parliamentary Technology Assessment

Grant Agreement no. 266649

Activity acronym: PACITA

Activity full name:

Parliaments and Civil Society in Technology Assessment

Deliverable 6.6

National report

Scenario workshop

in Austria

Due date of deliverable: June 2014

Final version: October 2014

Start date of Activity: 1 April 2011 Duration: 4 years

Author(s): Leo Capari and Mahshid Sotoudeh 
Organisation name of lead beneficiary for this deliverable: The Norwegian Board of Technology

Change Records

\begin{tabular}{|c|c|l|l|}
\hline Version & \multicolumn{1}{|c|}{ Date } & \multicolumn{1}{|c|}{ Change } & \multicolumn{1}{|c|}{ Author } \\
\hline 0.1 & 24.2 .2014 & Initial template for national reports & $\begin{array}{l}\text { Marianne } \\
\text { Barland, } \\
\text { Hilde Lovett }\end{array}$ \\
\hline 0.3 & 30.4 .2014 & Revision on template for reports & $\begin{array}{l}\text { Marianne } \\
\text { Barland, } \\
\text { Hilde Lovett }\end{array}$ \\
\hline 0.4 & Mai-June 2014 & Translations and production of the report & Leo Capari \\
\hline 0.5 & June-July 2014 & $\begin{array}{l}\text { Review and summary } \\
\text { This version is still in the reviewing process }\end{array}$ & $\begin{array}{l}\text { Mahshid } \\
\text { Sotoudeh, Leo } \\
\text { Capari }\end{array}$ \\
\hline 0.6 & July 2014 & $\begin{array}{l}\text { Executive summary is added } \\
\text { Layout }\end{array}$ & $\begin{array}{l}\text { Mahshid } \\
\text { Sotoudeh }\end{array}$ \\
\hline 0.6 & September 2014 & Spell check & DW \\
\hline 0.7 (fin) & October 2014 & Final review & Leo Capari \\
\hline & & & \\
\hline & & & \\
\hline & & & \\
\hline
\end{tabular}




\section{PACITA Partners}

Teknologirådet - Danish Board of

Technology (DBT)

Toldbodgade 12, DK-I253 Copenhagen, Denmark,

Contact: Marie Louise Jørgensen

mlj@tekno.dk

www.tekno.dk

\section{Karlsruhe Institute of Technology} (KIT)

Kaiserstr. 12, 76131 Karlsruhe, Germany Contact: Leonhard Hennen

leonhard.hennen@kit.edu

\section{Rathenau Insituut (KNAW-RI)}

Postbus 95366, 2509 CJ Den Haag, the Netherlands

Contact: Geert Munnichs

pacita@rathenau.nl/g.munnichs@rathenau.nl www.rathenau.nl

Teknologirådet - Norwegian Board of Technology (NBT)

Kongens gate 14, 0I52 Oslo, Norway

Contact: Marianne Barland

marianne.barland@teknologiradet.no

www.teknologiradet.no

The Institute of Technology

Assessment (OEAWIITA)

Address: Strohgasse 45/5, A-I 030 Vienna

Contact: Mahshid Sotoudeh,Pacita-ITA

team

pacita.ita@oeaw.ac.at

www.oeaw.ac.at

\section{FONDEN TEKNOLOGI RÅDET}

DANISH BOARD OF TECHNOLOGY FOUNDATION
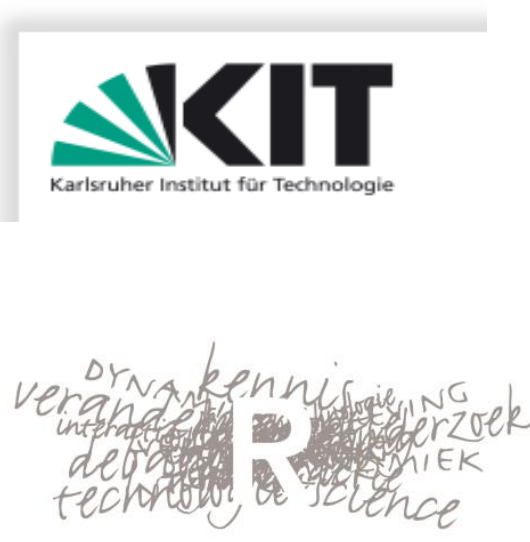

Rathenau Instituut
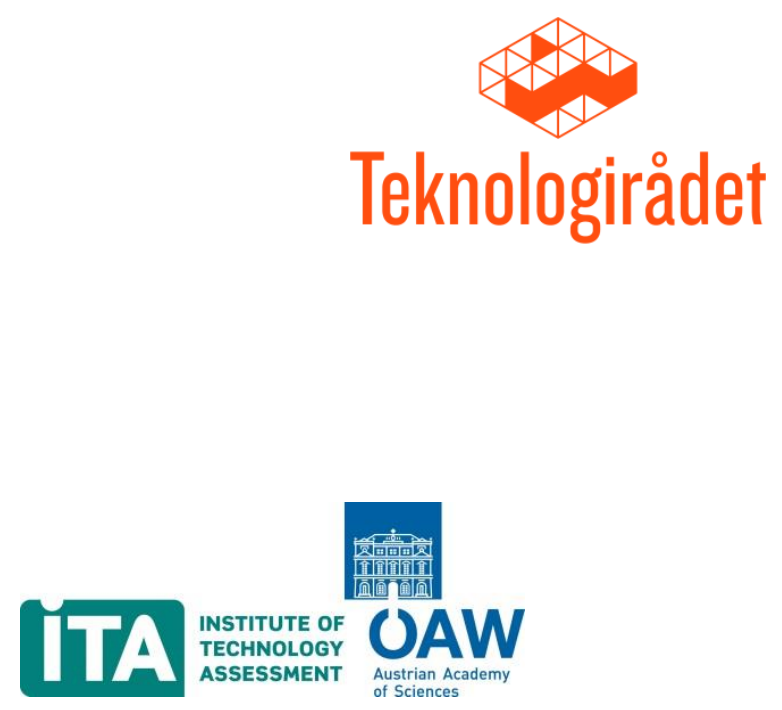
Applied Research and Communications Fund (ARC Fund)

5 Alexander Zhendov str., II I 3 Sofia,

Bulgaria

Contact: Zoya Damianova

zoya.damianova@online.bg

www.arcfund.net

Instituto de Tecnologia Química e

Biológica- Institute of Technology of biology and chemistry (ITQB)

Avenida da Republica, Estacao Agronomica Nacional,

Oeiras, 2784-505, Portugal

Contact: Mara Almeida

marasilvalmeida@gmail.com

www.itgb.unl.pt/

The Catalan Foundation for Research and Innovation (FCRI)

Pg. Lluís Companys, 23, ES-080I0

Barcelona, Spain

Contact: Belén López

belen.lopez@fundaciorecerca.cat

www.fundaciorecerca.cat

Swiss Centre for Technology

Assessment (TA-SWISS)

Brunngasse 36, $\mathrm{CH}-30$ II Berne,

Switzerland

Contact: Danielle Bütschi

danielle.buetschi@ta-swiss.ch

www.ta-swiss.ch

\section{Association Knowledge Economy Forum (KEF)}

Galvydzio 5/96, LT-08236, Vilnius, Lithuania Contact: Edgaras Leichteris edgaras@zef.It

www.zef.lt
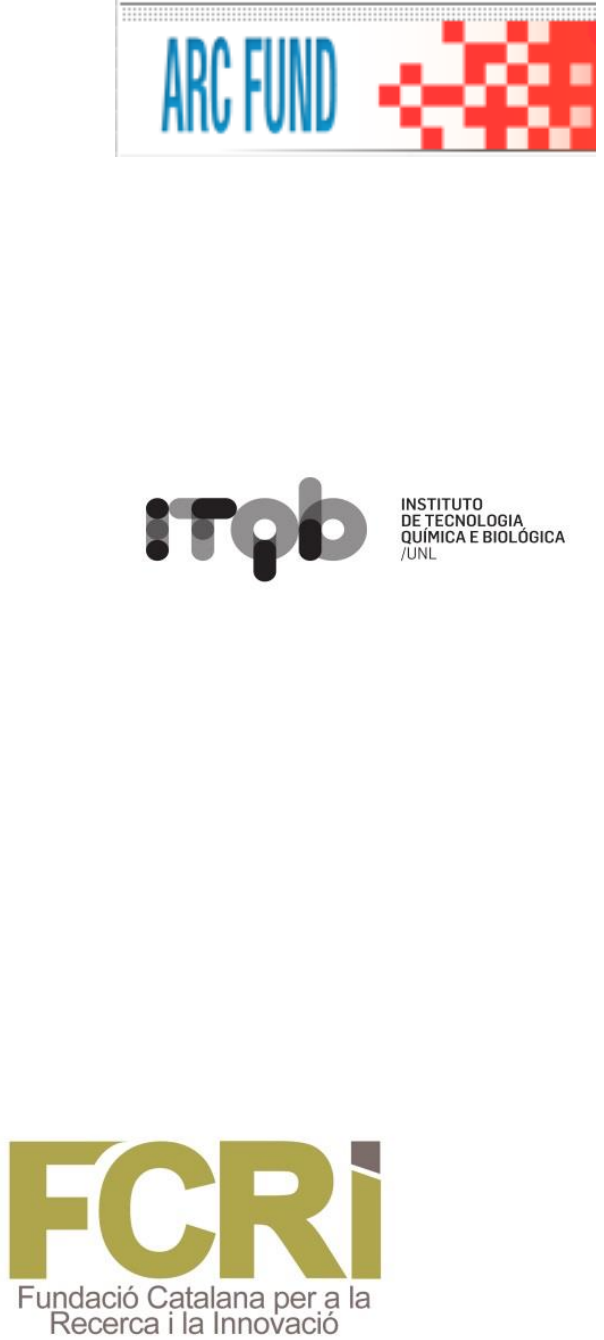

Zentrum für Technologiefolgen-Abschätzung Centre d'évaluation des choix technologiques Centro per la valutazione delle scelte tecnologiche Centre for Technology Assessment SWISS 
Technology Centre ASCR

Ve Struhach 27, 16000 Prague 6

Contact: Lenka Hebakova

hebakova@tc.cz

www.tc.cz

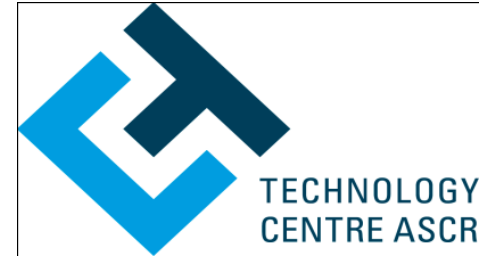

CENTRE ASCR

Scientific and Public Involvement in Risk Allocations Laboratory (SPIRAL)

Boulevard du Rectorat 7/29, B3I, 4000

Liège, Belgium

Contact: Pierre Delvenne

pierre.delvenne@ulg.ac.be

www.spiral.ulg.ac.be/

University College Cork (UCC)

Western Road, Cork, Ireland

Contact: Dr. Ciara Fitzgerald

cfitzgerald@ucc.ie

www.ucc.ie

Secretariat of the Hungarian

Academy of Sciences (HAS-SEC)

Nádor utca 7, H-I05I Budapest, Hungary

Contact: Katalin Fodor

fodor.katalin@titkarsag.mta.hu

www.mta.hu
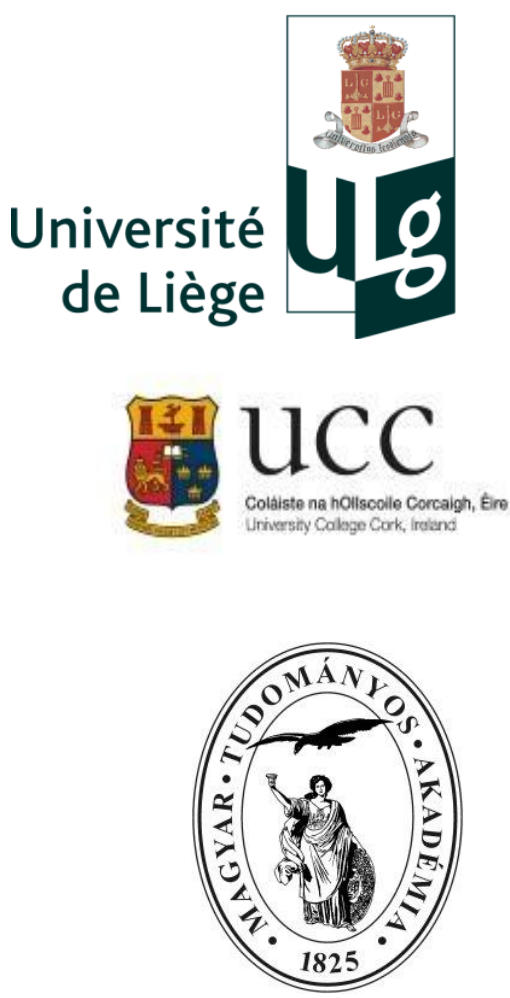

Legal notice:

The information in this document is provided as is and no guarantee or warranty is given that the information is fit for any particular purpose. The user thereof uses the information at its sole risk and liability. Neither the European Commission nor any person acting on behalf of the Commission is responsible for the use that might be made of the following information.

(C) PACITA 2012. Reproduction is authorised provided the source is acknowledged. 


\section{Table of contents}

$\begin{array}{lr}\text { 1. Introduction } & 10\end{array}$

2. National context 11

2.1 Local players and responsibilities in the care sector 11

2.2 National policies and status quo 12

2.3 The current Austrian care system 12

2.4 Challenges for the Austrian care system and reform efforts 13

2.5 Technological status and development 14

2.6 Local adaptations 15

3. Stakeholder workshop in Austria 16

3.1 Organisation of the workshop 16

3.2 Some words regarding the method 17

3.3 Recruitment process 19

$\begin{array}{lll}3.4 & \text { Participation } & 20\end{array}$

4. Results-Responses to the scenarios 21

4.1 Scenario 1: One size fits all 21

4.1.1 General response to scenario 1 (phase 1) 21

4.1.2 Positive responses to scenario 1 (phase 2) 21

4.1.3 Negative responses and concerns related to scenario 1

4.1.4 Dilemmas in scenario $1 \quad 22$

4.1.5 Other issues regarding scenario $1 \quad 22$

4.1.6 Differences of the groups' responses 23

4.2 Scenario 2: Freedom of choice 23

4.2.1 General response to scenario 2 (phase 1) 23

4.2.2 Positive responses to scenario 2 (phase 2) 24

4.2.3 Negative responses and concerns related to scenario 2

4.2.4 Dilemmas in scenario $2 \quad 24$

4.2.5 Other issues regarding scenario 2

4.2.6 Differences in the groups' responses 25

4.3 Scenario 3: Volunteering community 25

4.3.1 General response to scenario 3(Phase 1) 26

4.3.2 Positive responses to scenario 3 (Phase 2) 26

4.3.3 Negative responses and concerns related to scenario $3 \quad 26$

4.3.4 Dilemmas in scenario $3 \quad 27$

4.3.5 Other issues regarding scenario 3 27

4.3.6 Differences of responses of the group 27

4.4 Additional remarks to the three scenarios: 28

5. Analysis and synthesis of visions and recommendations from Austria 29

5.1 Overview of visions 29

6. Clustering of the consensus visions according to their main topic 37 
6.1 Recognition and acknowledgement of individual needs 37

6.2 Self-determination, autonomy and freedom of choice 37

6.3 Guaranteed basic care provision 37

6.4 Participation and inclusion 37

6.5 Technology as support 38

6.6 Quality assurance 38

7. Synthesis of recommendations \& visions in the national policy context 39

$\begin{array}{lll}7.1 & \text { Recommendations } & 41\end{array}$

7.1.1 Assurance and recognition of individual needs 41

7.1.2 Self-determination, autonomy and freedom of choice 41

7.1.3 Guaranteed basic care provision 42

7.1.4 Participation and inclusion $\quad 42$

7.1.5 Framework conditions (legal, social, economic, norms \& standards) 42

7.1.6 Need for the education of personnel working for and with older adults, and education for older adults 43

7.1.7 Changing the public perception of older adults 43

7.1.8 Use of technology and privacy issue 43

7.1.9 Technology 43

8. Summary and concluding remarks 45

8.1.1 A short overview of the general reactions to the scenarios "One size fits all",
"Freedom of choice" and "Volunteering community" are:

8.1.2 Dilemmas in scenario $1 \quad 45$

8.1.3 Dilemmas in scenario $2 \quad 45$

8.1.4 Dilemmas in scenario $3 \quad 45$

8.1.5 Putting into national context 46

$\begin{array}{ll}\text { Appendix A: List of participants in the scenario workshop } & 48\end{array}$

$\begin{array}{lr}\text { Appendix B:Photos } & 50\end{array}$ 


\section{Executive summary}

Demographic change faces the Austrian healthcare system with new challenges concerning the provision with (health) care services for older adults. The challenges in Austria are primary perceived as a problem for the pension system, the healthcare system and the care system, and for older adults. According to forecasts, in $203024 \%$ of the Austrian population will be aged 64 and older. The Austrian health care system is based upon a compulsory social insurance system. Technologies like assistive technologies, telecare or telemedicine solutions have become of great interest. The discussion on access to telecare and telemedicine is influenced among other things by the heterogeneous care system in Austria resulting from Austrian federalism. Public health services and administration are provided jointly by federal, provincial and local authorities. In addition, the provinces are in charge of ensuring hospital care for their inhabitants as well as offering health promotion and prevention services. The local authorities are responsible for social welfare benefits and services. Due to the diversification of powers and the federal structure of the health care system, there is considerable need for the coordination of these instances/actors. The central regulatory instrument in this context is "Art. 15a of the Federal Constitutional Act". This agreement is a treaty between the federal government and the nine federal states of Austria and guarantees the financing, organization and coordination of the health care system on a four-year basis.

The care system is "causally oriented", which means that the services are not based upon needs. They are based upon the reasons for the needs. Therefore the same needs resulting from different reasons may be treated differently (e.g. different service provision in the case of leisure accidents or work accidents).

The function of the care system depends very much on informal care (mostly by female family members). In comparison to Scandinavian countries, informal care plays a central role in the care system of Austria (this also holds true for other central European countries) ${ }^{1}$. One of the reasons for this is the fact that cash benefits alone are far from sufficient to cover the costs of the care and assistance. ${ }^{2}$

\section{The PACITA-stakeholder scenario workshop:}

In this context, the PACITA-stakeholder scenario workshop, which was held in Austria on 26 March, gave stakeholders from different professions and with different interests in the care sector space to critically discuss and reflect on the scenarios provided by the PACITA project team. In addition, during the one day workshop they had the opportunity to formulate their visions on care provision for the year 2025 in Austria and the role that technology plays in this context.

\section{Key results:}

The general reactions to the scenarios "One size fits all", "Freedom of choice" and "Volunteering community" show the need for a multidimensional governance and a new orientation of care in the society. The main concerns are:

- Replacement of professional care personnel by technology. Technical innovations, be it telemedical, telecare or AAL devices in a broader sense, are just one part of the puzzle for coping with the challenges of demographic change. The stakeholders agreed on the aspect that technology for care can only serve as support and not as a substitution for professional care.

- Privacy concerns resulting from the use of care technologies. A dilemma between surveillance and more security was identified in scenario 1 . In scenario 3 the "unknown" volunteers would have access to the private environment.

- Potential for social pressure: "Here, this care package is for you. What, you don't want it? This means trouble! Don't be rebellious!" Will there be alternatives and ways of saying "No, I don't want any support!" (i.e. non-technology alternatives).

- Potential risk that the disparity between rich and poor may become greater within scenario setting 2, which is mainly market-oriented.

\footnotetext{
${ }^{1}$ http://www.oeksa.at/files/publikationen/broschuereLangzeitpflege.pdf

${ }^{2}$ http://www.politischebildung.com/pdfs/34_nowak.pdf
} 
The main needs are felt to be:

- assurance of the good quality of care and a consideration of special care needs. Aging well is about living well.

- individual needs should be acknowledged and recognised instead of the current system in Austria, which is based on the reason for the needs. The competences and needs of older adults should be taken into account, not only in the R\&D process of the technologies, but also in the care and assistance sector itself.

- a broad social debate on a new orientation of the care system that considers technical and social innovations and can deal with the challenge of demographic change

- this debate should also include awareness increasing and the provision of information for relatives and the ways to relieve the burden on them

- access to information, since informed decisions need to be based on good and available information. This means that the market needs to be transparent and information needs to be (made) available to everybody.

- early preparation for ageing requires new training approaches and coaching concepts

- initiatives and self-organization of relatives/caregivers and communities should be supported

The results of the stakeholder workshop (feedback on the scenarios, visions \& recommendations) emphasize:

- Self-determination, autonomy and freedom of choice

- Guaranteed basic care provision

- Participation and inclusion

- Use of technology in the context of privacy-enhancing and social innovations

Furthermore the results of the workshop show clearly that technology alone is not enough to cope with the challenges of an ageing society. People should be given the free choice of the support that they wish to use. Technology as a tool has the purpose to...

..."make life easier and help in everyday life, but not only control (i.e. constant monitoring). Technology can be a motor to bring people together (chats).

Technical systems should be individually configurable and adaptable. Basic care packages are defined through standards, norms and quality directives. Personal data is the property of the users and they decide what, where and for how long this data is saved." (Chapter 5, T6-Common Vision 1)

Throughout the workshop the Austrian government was mentioned repeatedly as having the responsibility to ensure the provision of good care for the citizens. This is a feature of a classical welfare state. When it comes to the development of technologies, the government has the responsibility to set up regulations and to define standards, the aim of which is to "lead" the R\&D processes and to prevent a diverse proliferation. 


\section{Introduction}

How to cope with ageing societies is one of the great challenges pointed out in the Lund Declaration [Lund 2009]. The rapidly growing population of senior citizens ${ }^{3}$ confronts Europe with a double demographic challenge. The ageing population's need for healthcare services increases at the same time as the access to the available workforce declines ${ }^{4}$.

The use of technology can be increasingly important for society's ability to offer health care services at a quantity and quality that mirrors the expectations of the European populations. Our society can choose different strategies for the care services and for the introduction of new technological tools in this sector. The technology promises many opportunities, but there are challenges to be solved and ethical dilemmas to be considered. How can we best use new technology in care services, what is acceptable and what is the resistance of the senior citizens themselves, and what type of options are policy-makers faced with?

To facilitate and provoke forward-looking discussions and identify policy alternatives the PACITA project has conducted nine national and regional scenario workshops in, Denmark, Czech Republic, Hungary, Catalonia (Spain), Norway, Wallonia (Belgium), Switzerland, Austria and Bulgaria. A scenario workshop is a method aimed at facilitating forward-looking discussions and identifying policy alternatives in different contexts. In PACITA, the workshops are intended to stimulate discussions on how the needs can be met and how the challenges of the rising number of older adults in different European countries can be faced, with a set of scenarios as a starting point for the discussion.

To create awareness of the possible consequences of political choices, the participants were presented with three scenarios; "One size fits all", "Freedom of choice" and "Volunteering community". They differ with respect to the degree to which public and private players provide elderly care in the future and how the senior citizens and other groups in society organise themselves in order to meet the needs for care. To create awareness of the possible consequences of the choices, the participants were also presented with user stories depicting four people, and how they could be living their lives in 2025 in the given scenarios.

The scenarios and user stories have been used to provoke discussions in scenario workshops on how one can meet the needs and face the challenges of the rising number of older adults in the European countries. The scenario workshops in the PACITA project have produced visions for what kind of elderly care services the Europeans (through the views of a diverse range of elderly care stakeholders) want and the policies envisaged to achieve these visions.

This report summarises and analyses the results of the national scenario workshop held in Austria, on $26^{\text {th }}$ March 2014.

The findings from the nine national workshops will be gathered and analysed in a synthesis report, to be presented to regional, national and European policy-makers at a policy conference in Brussels in late 2014.

\footnotetext{
${ }^{3}$ The term ,elderly“ is commonly used. We are aware that this is a sensitive terminology. We have chosen to use the more neutral term "senior citizen" throughout this document.

${ }^{4}$ An ageing population is defined as a population in which the number of elderly (65+) is increasing relative to the number of $20-64$ year olds. http://www.population-europe.eu/Library/Glossary.aspx
} 


\section{National context}

\section{Background}

The prognoses for demographic development in Austria reveal a shift in the age distribution for the upcoming 20 years. One of the reasons for this is the higher life expectancy in general. In combination with lower birth rates and the relatively strong birth cohorts of the 1960's, who are still in employment, Austria is facing new challenges. According to forecasts, these cohorts will have undergone a transition to the retired population in 2030, resulting in 24\% of the Austrian population being aged 64 and older. This shift has led to the crucial question of how best to support older adults at home in the future. According to a forecast by the Austrian Federal Institute for Healthcare (ÖBIG) nearly 22500 more full time equivalents for long term care (LTC) will be needed by $2025^{5}$ (Fig. 1).

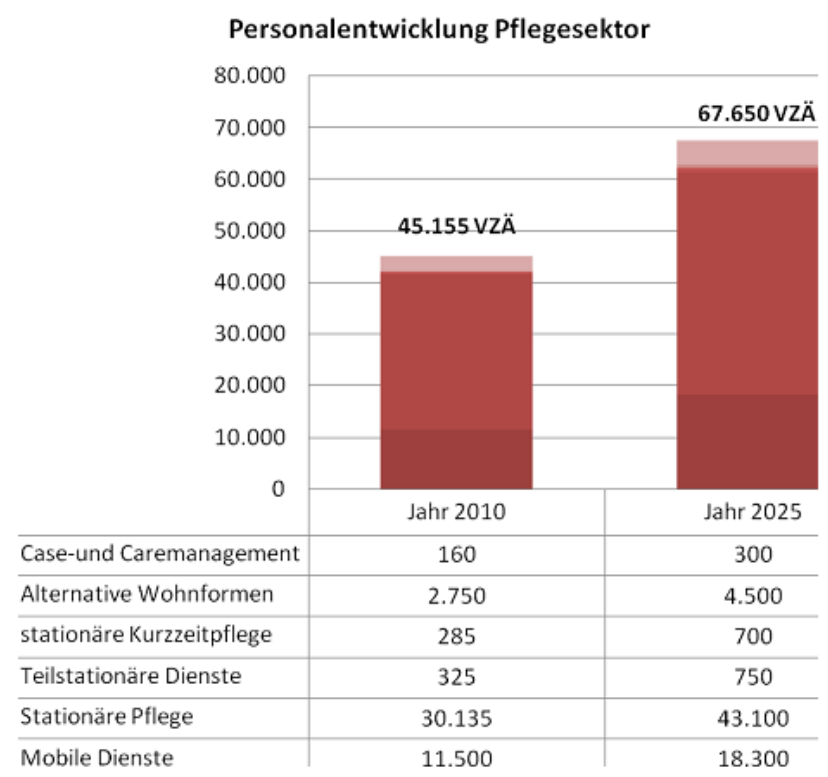

Figure 1: The forecast of the workforce needed up to 2025 in Austria. Nearly 22500 more full time equivalents are needed to satisfy the increasing demand for personnel in the care sector.

"benefit", the national AAL research programme (part of the EU Ambient Assisted Living Joint Programme AAL $\mathrm{JP}^{6}$ ), launched by the Federal Ministry for Transport, Innovation and Technology (BMVIT), was initiated in 2007. The calls under the "benefit" programme focus on "ICT-based Solutions for the Advancement of Active Ageing" and include social inclusion, comfort and security aspects as well as activities within and outside the home environment. In addition, interdisciplinary platforms like AALAustria or ÖPIA (Austrian platform for interdisciplinary questions of ageing) were established in order to foster the visibility of AAL themes in public discussion (AAL - Austria) and to provide an interdisciplinary communication platform between science, public and politics (ÖPIA).

\subsection{Local players and responsibilities in the care sector}

The Austrian health care system is based upon a compulsory social insurance system. This compulsory insurance system includes a pension insurance, health insurance and accident insurance scheme.

\footnotetext{
${ }^{5} \mathrm{http} / / /$ www.sozialministerium.at/cms/site/attachments/9/7/0/CH2081/CMS1356078635988/goeg_kostenprognose2010_2025.pdf

${ }^{6} \mathrm{http}: / /$ www.aal-europe.eu/
} 
The main actors in the health care system are the Austrian Parliament, the Federal Ministry of Labour, Social Affairs and Consumer Protection (BMASK), the Federal Ministry of Health (BMG), the social security institutions and advocacy groups (i.e. social partners: employers' and employees' representatives, as well as professional associations) ${ }^{7}$. The competences of the health care in Austria are regulated by law. Some of the competencies lie not only within the federal government (legislation and enforcement). These competencies are therefore delegated to the federal states or to social security institutions. A total of 22 social insurance institutions provide health, pension and work accident insurance in Austria. They are organised in an umbrella organisation called the "Main Association of Austrian Social Insurance Institutions" (Hauptverband der österreichischen Sozialversicherungsträger ${ }^{8}$ ).The Federal Ministry of Health (BMG) has a central role in the preparation of laws, but also in the facilitation and coordination between the different actors in the health care system and in decision making and supervisory tasks.

Due to the diversification of competencies and the federal structure of the health care system, there is a great need for the coordination of these instances/actors. The central regulatory instrument in this context is "Art. 15 a of the Federal Constitutional Act". This agreement is a treaty between the federal government and the nine federal states of Austria, and guarantees the financing, organization and coordination of the health care system on a four-year basis.

Austria's health care expenditure accounts for $11.1 \%$ of Austria's GDP $(2012)^{9}$. Roughly three quarter of this amount is financed by public instances (i.e. government, federal states, municipalities and social insurance institutions), with almost one quarter of the expenditures financed through private investments ${ }^{10}$ (e.g. private households and insurance companies). According to the OECD Austria spends more on health per capita than the OECD average ${ }^{11}$. In addition, compared to other OECD countries Austria has a higher number of physicians per capita.

\subsection{National policies and status quo}

Public health services and administration are jointly provided by federal, provincial and local authorities. In addition, the provinces are in charge of ensuring hospital care for their inhabitants as well as offering health promotion and prevention services. The local authorities are responsible for social welfare benefits and services. As already mentioned before, one of the main political instruments for the health care system is "Art. 15a of the Federal Constitutional Act", which guarantees the financing of the health care system (including care for the elderly) on a four-year basis (treaty between the federal government and the nine federal states). Further important planning instruments in the health care sector are the Austrian Health Care Structure Plan (ÖSG) and the Regional Health Care Structure Plans (RSG). These plans are of central importance when it comes to the planning and distribution of resources across all levels in the health care sector and the provision of services ${ }^{12}$. Another important instrument in this sense is the staffing plan for physicians who are in a contractual relationship with the health insurance funds.

\subsection{The current Austrian care system}

The care system is "causally oriented", which means that the services are not based upon the needs. The services are based upon the reasons for the needs. Therefore the same needs resulting from different reasons may be treated differently (e.g. different service provision for leisure accidents or work accidents). The system is mainly based on a compulsory insurance principle ${ }^{13}$.

\footnotetext{
${ }^{7}$ http://www.goeg.at/cxdata/media/download/berichte/bmg broschuere e 2013.pdf ; page 7

${ }^{8} \mathrm{http} / / / \mathrm{www}$. sozialministerium.at/cms/site/attachments/1/6/3/CH2088/CMS1313745345149/social_protection in_austria.pdf

${ }^{9} \mathrm{http}: / /$ www.statistik.at/web_de/statistiken/gesundheit/gesundheitsausgaben/

${ }^{10}$ http://www.politischebildung.com/pdfs/34 nowak.pdf

${ }^{11} \mathrm{http} / / / \mathrm{www}$. oecd.org/els/health-systems/Briefing-Note-AUSTRIA-2013.pdf

${ }^{12}$ http://www.bmg.gv.at/cms/home/attachments/2/1/2/CH1015/CMS1287855495948/the austrian health care system 2010 e1.pdf

${ }^{13} \mathrm{http}$ ://www.oeksa.at/files/publikationen/broschuereLangzeitpflege.pdf Seite 129
} 
The 1993 care agreement between the federal government and the nine federal states is implemented in "Art. 15 a of the Federal Constitutional Act" and is based on a two-pillar system. The two pillars are,

1. Cash benefits in the form of "Pflegegeld", which was introduced in 1993 and is mainly the responsibility of the federal government, and

2. Benefits in kind or "Sachleistungen", which are delivered in the form of social services. The benefits in kind are delivered by the nine federal states.

In Austria all persons who are eligible for long-term care services regardless of their age receive cash benefits. Eligibility is assessed by a doctor and experts based on IADL (instrumental activities of daily living). The cash benefits are tax-free and come in seven different levels, ranging from level 1 with a "Pflegegeld" payment of $154.20 €$ (i.e. where more than 60 hours care per month is needed) to level 6/7 with a payment of $1260 € / 1655,80 €$ (i.e. where more than 180 hours per month are needed and there are additional physical and mental impairments).

The second pillar of the system, benefits in kind, is provided by the federal states. In addition the use of benefits in kind is the responsibility of the individuals. These services include mobile services (e.g. domicile care, home helpers, 24-hour care etc.), outreach services (e.g. outreach therapeutic services and regional advisory or counselling centres), semi-institutional centres (e.g. day centres), in-patient/institutional services (e.g. short-term care, nursing homes, residential homes etc.) and services for people with disabilities (e.g. transport service, personal assistance, occupational therapy etc.). The cash benefits may be used to cover the costs of kind services. ${ }^{14}$ The access to and financing of the benefits in kind is regulated by laws and regulations, which in part vary between the federal states, making the care system opaque and difficult to follow.

The functioning of the care system depends very much on informal care (mostly by female family members). In comparison to Scandinavian countries, informal care plays a central role in the care system of Austria. ${ }^{15}$ One of the reasons for this is the fact that the aforementioned cash benefits alone are far from sufficient to cover the costs of the care and assistance. ${ }^{16}$

\subsection{Challenges for the Austrian care system and reform efforts}

The Austrian health care and especially care for the elderly will face several challenges in the future. Demographic change in combination with the increasing employment of women, especially in the light of the significant importance of informal care and the increasing individualisation of the society, makes reforms necessary. Furthermore the distribution of financial and political responsibilities between the federal government and the federal states needs to be discussed. The current situation of the federal system and the in part fuzzy distribution of responsibilities (administrative fragmentation) often leads to undersupply, oversupply and sometimes also to inappropriate health care. ${ }^{17}$ First reforms have already been accomplished in the form of the implementation of the "care fund", which was introduced in 2011 by the Federal Ministry for Social Affairs. It is a step towards securing the financing of the increasing costs for care in local government authorities and the federal states in the time frame from 2012-2014. In addition a simplification of the administration of cash benefits was adopted. Cash benefits are now administrated by the federal government only. This simultaneously raised concerns about the increasing centralisation and the fear that individual needs or regional differences concerning care demands will be neglected.

The latest and also rather comprehensive reform efforts for the care sector started in 2011 as a care reform work group (CRW) between federal government, federal states and representatives of the system partners (stakeholders, Austrian Medical Chamber, Main Association of Austrian Social Insurance Institutions, older adults, service providers, employees, employers).

\footnotetext{
${ }^{14} \mathrm{http}: / /$ www.oecd.org/health/health-systems/47877397.pdf

${ }^{15} \mathrm{http}: / /$ www.oeksa.at/files/publikationen/broschuereLangzeitpflege.pdf

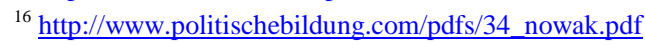

${ }^{17}$ http://www.patientenanwalt.com/download/Expertenletter/Gesundheitswesen/Integrierte_Versorgung_im_Gesundheitswesen_Mag_Karin_Eger_Ge sundheitswesen.pdf
} 
In mid 2013 they presented a reform document, which included 35 recommendations and cover measures in the following fields. ${ }^{18}$

- Improvement of the provision of assistance and care

- Caring relatives

- Personnel

- Financing

The aims behind these reform efforts are for 1) improve the care supply, 2) to relieve the burden on caring relatives 3) to make care jobs more attractive and 4) to optimize the financing of the care sector. The recommendations propose new concepts in the education of care personnel, the implementation of AAL systems to foster autonomous living in the personal living environments, prevention, mobilisation of older adults, dedicated measures for persons suffering from dementia etc. We have found that several recommendations and measures proposed by the care reform work group cover similar aspects to those in the recommendations and visions of the stakeholders. In addition, the policy document "Ageing and future Governmental plan for elderly persons"19 also addresses several aspects which were discussed by the stakeholders. This document constitutes a national plan, and was developed by the Federal Ministry of Labour, Social Affairs and Consumer Protection (BMASK) in cooperation with the National Elderly People Advisory Council. The aim of this document is to provide a framework for politics and to ensure and enhance the life quality of older adults by developing objectives and recommendations. For this reason, we will present a first comparison of the results of the PACITA-stakeholder workshop with these recommendations in the conclusion chapter.

\subsection{Technological status and development}

Telecare, telemedicine and AAL are not sharply divided concepts/classifications in Austria. According to the definition of working group 7 of the eHealth Initiative in the "Draft for the Austrian e-Health strategy", 20 telemedicine services are defined as the therapy (incl. diagnosis) of a patient without the patient being present at the location of the service provision (medicine at a distance). This service is achieved by the use of electronic support systems (telecommunication and informatics). These support systems are intended to supplement the treatment of the patient. The major aim of telemedicine services is that the expertise comes to the patient and not the opposite way around. Furthermore this allows access to medical services to be independent of the patient's location (domicile). Telemedicine includes the following areas:

- teleradiology, telepathology and other tele-diagnostic services

- teleconsulting, telesurgery

- tele-home monitoring

- teletriage

- possibilities for a quicker treatment due to a better preparation of the doctor through the receipt of relevant diagnostic findings in advance

In the position paper on AAL (Ambient Assisted Living) of the eHealth Initiative (2012/2013), ${ }^{21}$ AAL refers to concepts, products, services, technologies and systems which use ICTs to assist older adults and persons with special needs in their daily life. The overall aim of AAL is it to increase the life quality and autonomy of the target group. This is achieved by means of ICT through the provision of a sensitive and adaptive living environment. Their use is supposed to be intuitive, and the AAL system should adapt itself to the user and not the other way around.

AAL systems are intended to provide support in the following areas:

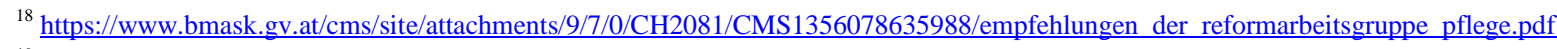

${ }^{19} \mathrm{http}: / /$ www.sozialministerium.at/cms/site/attachments/4/7/6/CH2229/CMS1218014040042/bundesseniorenplan_kompl.pdf

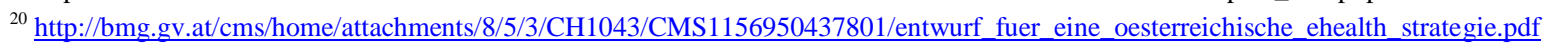

${ }^{21}$ http://ehi.adv.at/fileadmin/user_upload/adv_author/pdfs/Positionspapiere2013/2013-04-03_Positionspapier_eHI-AG_AAL_v1.0.pdf
} 
- health, medicine, care and mobility

- household chores, daily routine

- communication and contact

- increase in security

- leisure time

Subdivisions within the abovementioned areas are telemedicine, telecare, telemonitoring, emergency systems, systems that recognize falls etc.

In Austria currently the commonest technology which can be defined as telecare technology is personal alarm systems. According to a study in 2008 carried out by the Institute for Empirical Social Studies (IFES), almost three quarters of people over 70 years know about the existence of such devices, while $8 \%$ of these people personally own and use personal alarm systems. About half of the people said that they can imagine using such systems in the future. The barriers against the use of these systems are mainly the fear of high prices and the concern that they are complicated to use. ${ }^{22}$ Personal alarm buttons are offered by various companies for private use. Care organisations like the Red Cross also offer them as an additional option to their mobile care services for roughly 20-25€/month. Further technologies are monitoring devices for health related data, video-based fall detectors combined with automated alarm systems, sensor mats that recognize falls and telecare/telemedicine solutions for home, public or mobile use. A service robot is currently being tested in a Viennese care home. The robot, named Henry, ${ }^{23}$ was developed in an EU project under the Seventh Framework Programme and has a monitoring function in the care home. The robot is equipped with 3D cameras which analyse the surrounding environment, and in the event of an emergency it can trigger an alarm.

The Austrian AAL Platform (AAL Austria) is actively working to create a national network between different stakeholders and users and also to draft recommendations for decision makers and research, provide information for different actors and organise events of various kinds (workshops, working groups, forums etc.). A further step towards market-ready AAL technologies is the integrAAL project, which is funded under benefit; the national AAL-scheme. This project is intended to define a guideline for the "proper" implementation, use and financing of AAL technologies in test regions. The background for this project lies in the fact that considering the heterogeneous national and international developments of AAL technologies/solutions, the technologies have still not achieved market readiness. The guideline produced in the integrAAL project is intended to promote the market readiness and the visibility of the technologies involved.

Summing up, telecare, telemedicine and AAL technologies in general are not used broadly in Austria (except for alarm buttons). This was also confirmed by one stakeholder who participated in the scenario workshop. He mentioned that his company offers market-ready products, but Austria is not the primary sales market for various reasons (such as infrastructural and political). Stakeholder recommendations for social and organisational innovations prior and parallel to AAL are listed in section 8.1.

\subsection{Local adaptations}

The names of the persons in the scenarios were changed. We also tweaked the scenarios regarding the responsibilities for e.g. service provision in Austria. The Austrian local government authorities and the federal states are assumed to be the main entities responsible in future health care provision (as it is today).

\footnotetext{
${ }^{22} \mathrm{http}: / /$ www.sozialministerium.at/cms/site/attachments/5/1/4/CH2232/CMS1218014508393/studie senioinnengerechte produkte.wien 2013.pdf

${ }^{23} \mathrm{http}: / /$ strands.acin.tuwien.ac.at/project.html
} 


\section{Stakeholder workshop in Austria}

\subsection{Organisation of the workshop}

The Austrian PACITA-scenario Workshop on "Teleassistance and future ageing" was held on $26^{\text {th }}$ March 2014 in Vienna. The organizer of this event was the Institute of Technology Assessment (ITA). The venue was the main building of the Austrian Academy of Sciences. The agenda of the workshop is depicted in Table 1.

Table 1: The agenda of the scenario-Workshop in Austria

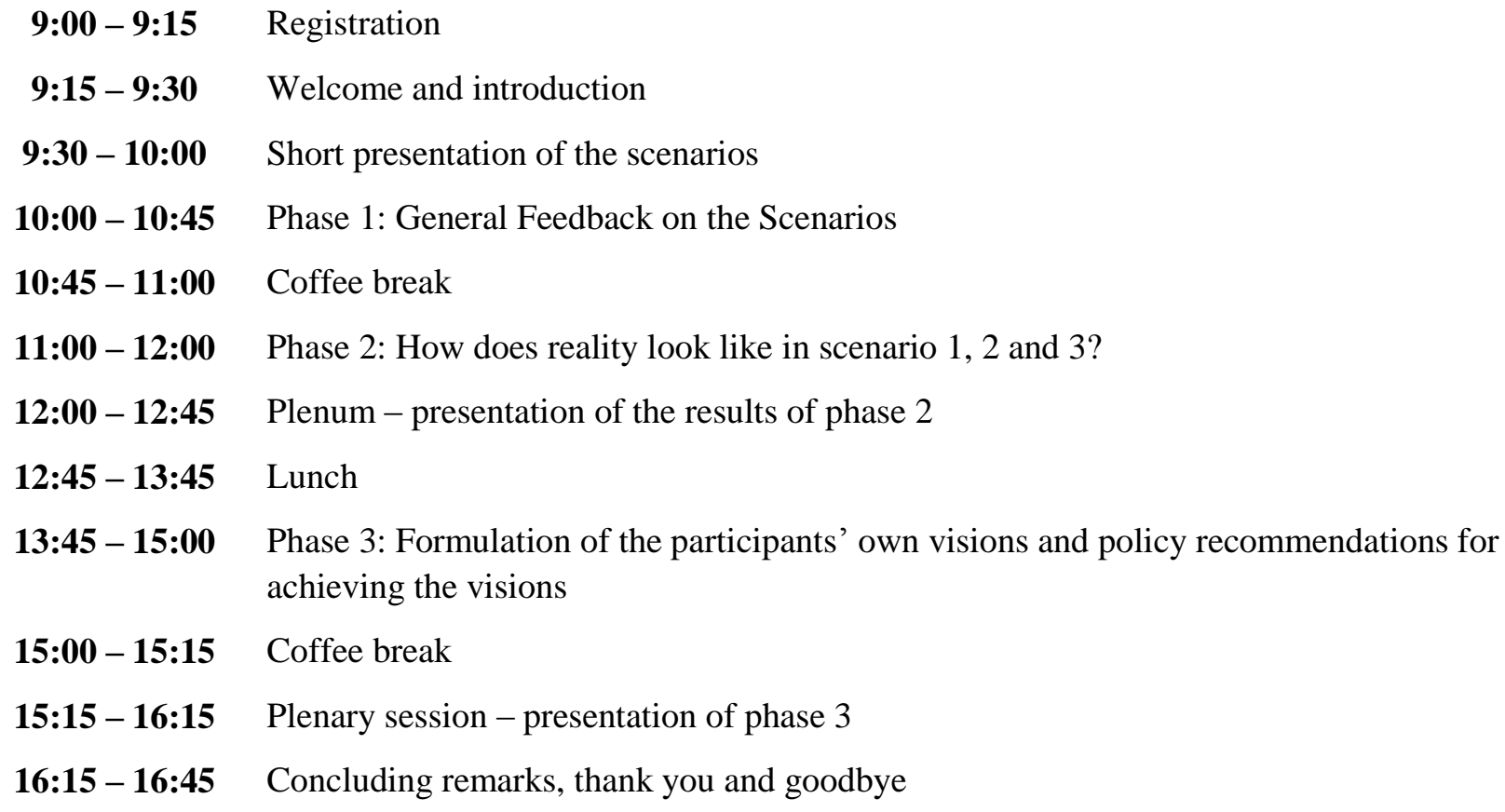

\section{Some comments on the practical side of the workshop:}

The team for the Austrian scenario workshop consisted of 13 people (one main facilitator and moderator, six table moderators and six rapporteurs). A training session for all team members was organized in order to prepare the table moderators and the rapporteurs for the workshop. In this session they were familiarised with the method, and comprehension questions regarding the scenarios were also discussed.

Figure 1 shows the distribution of stakeholders during the first two phases. Each table had a specific thematic focus, which was reflected by the participants" "function" (stakeholders). At table 1 (T1) stakeholders from research \& development and companies were represented. Table 2 (T2) was occupied by stakeholders, who play a role as interdisciplinary policy advisors, as their work has an influence e.g. on national research programmes. Stakeholders on table 3 (T3) were representatives of local care institutions and politicians from the health care sector. Stakeholders on table 4 (T4) represented medical and care personnel (or service providers). At table 5 (T5) care researchers and at table 6 (T6) representatives of older adults and caring relatives discussed the scenarios. 

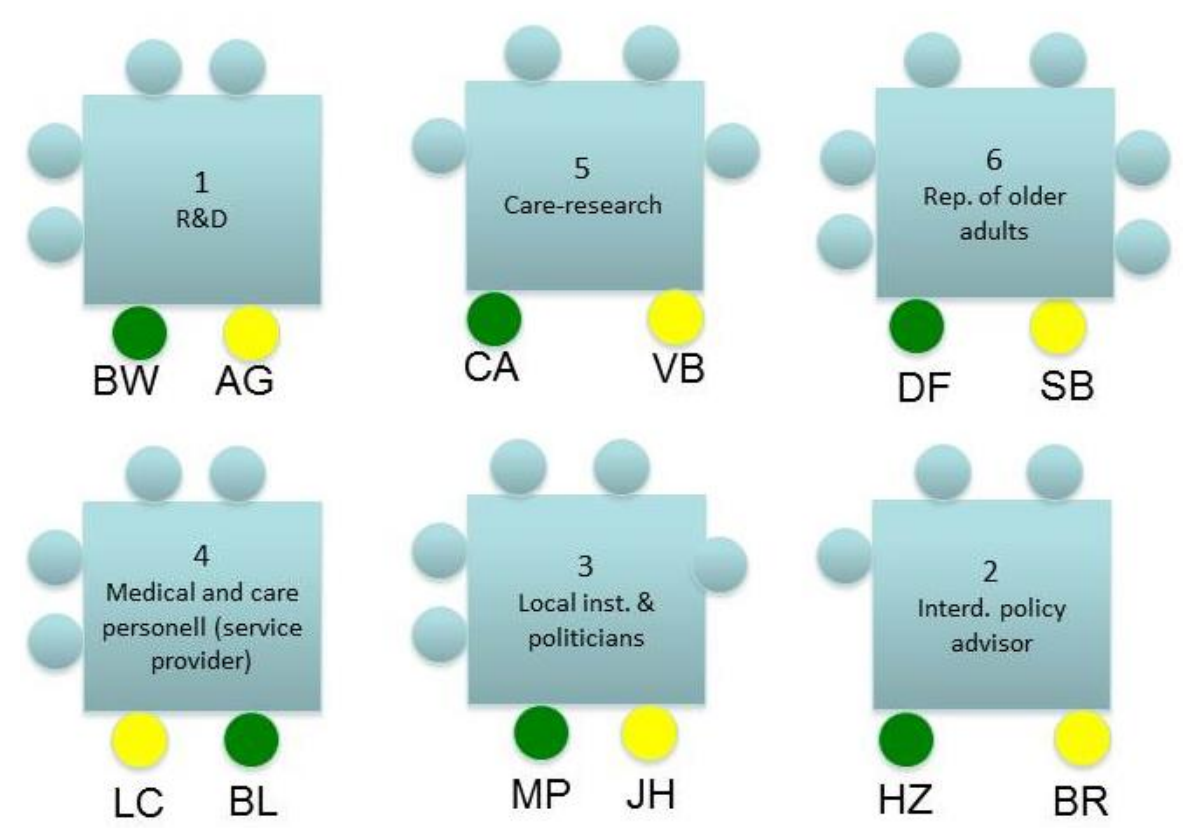

Figure 2: Set up of the tables and distribution of participants during phase 1 and phase 2 of the workshop (homogenous groups). At each table one moderator and one rapporteur was present (initials represent the names of moderators and rapporteurs)

\subsection{Some words regarding the method}

The method for the scenario workshop was structured in order to guarantee an efficient and aim-oriented procedure. During the presentation and introduction of the scenarios in the plenary session the stakeholders received a short questionnaire. Participants were asked to answer for each scenario,

- Is it a possible scenario for the future situation in Austria?

- Is it a realistic situation for the future?

- Is it a desirable situation?

- And finally, what positive and negative impacts are expected from this scenario?

This questionnaire gave them the possibility to make notes regarding each scenario during the presentation. Furthermore this helped the table moderators to structure the discussion in Phase 1 during the workshop. For Phases 2 and 3 we decided to ask participants to write their ideas on post-its and make them visible to everybody at the table. We used pinboards (one per table) and A3 papers with the guiding questions from the scenario document. For each guiding question, post-its were prepared for the stakeholders to record their answers to the guiding question. Figures 2 and 3 show the set up for these two phases. 


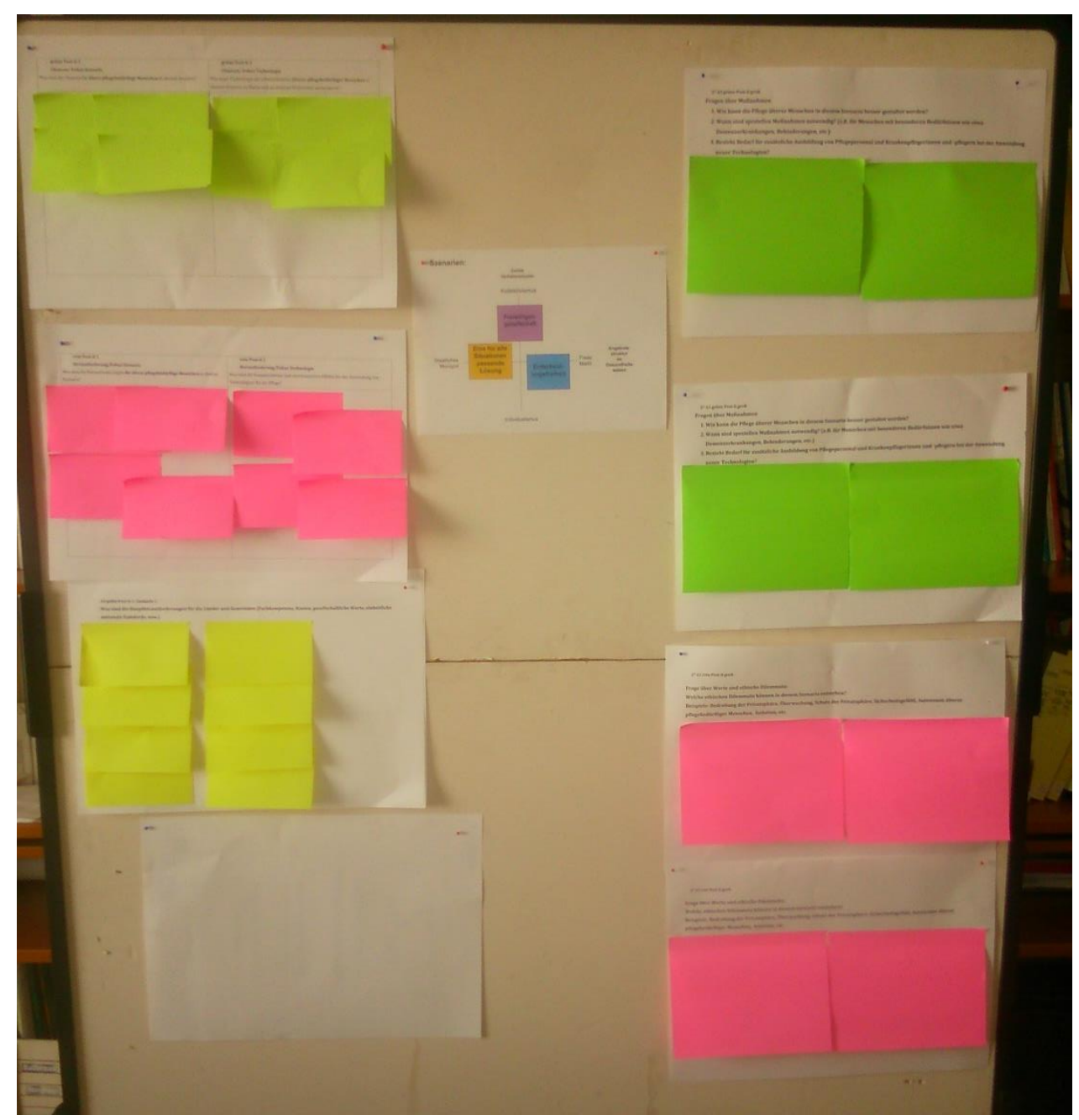

Figure 3: Structure of phase 2. The beginning is at the top left and the end is at the top right. Green small post-its provide space for positive aspects of the scenario given (divided into context-based and technology-based), while the small red post-its indicate negative aspects for the scenario given (also divided into context-based and technology-based challenges). The small yellow post-its are for the challenges for local government authorities and the federal states. The large red post-its provide space for the ethical dilemmas which were identified in the scenario given, whereas the large green post-its provide space for measures for improving the given scenario. After writing them down, each stakeholder presented his/her thoughts to the other stakeholders on the table. Similar post-its were clustered together. 


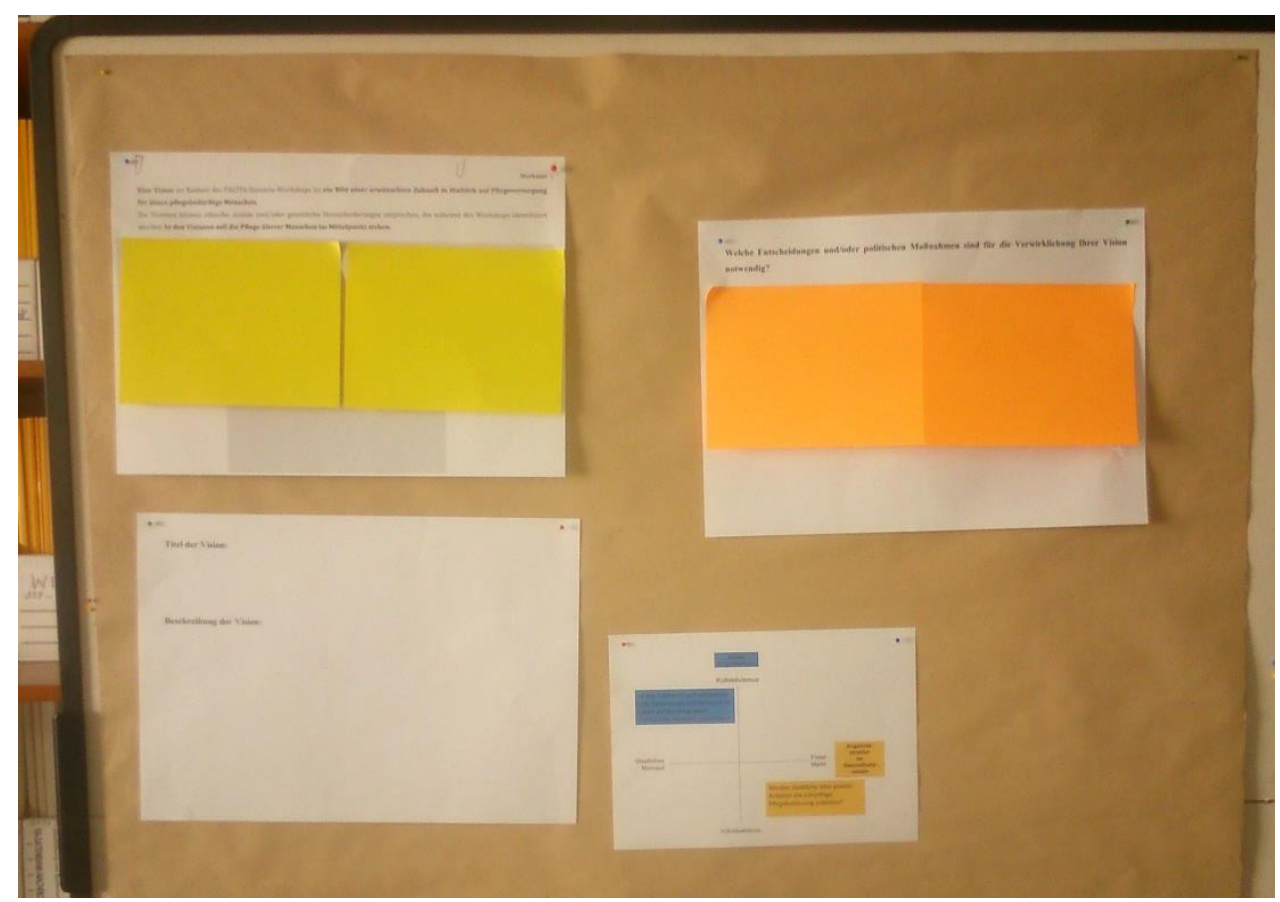

Figure 4: Structure of phase 3 during the workshop. Each stakeholder wrote his/her desired future (vision) on the yellow post-its, and then presented it to the group. This was followed by a discussion on all the visions presented and the finding of consensus on one or two visions for this table. The orange post-its were for the measures and/or policies which are necessary in order to achieve these visions. We also provided the coordinate system of scenarios (bottom right of the picture) in which the stakeholders could localize their visions.

\subsection{Recruitment process}

The recruitment process started in late November/early December. First of all we composed a list of potential and relevant stakeholders for the workshop (desk research). We also opened a doodle for the coordination of the date for the workshop. In the next step we sent an email with the invitation to the workshop including the doodle poll to the anticipated participants. When March 26 was indicated as being the date on which the most people could participate, we closed the doodle. Stakeholders who did not react to the doodle were invited again with the specific date of the March 26. The recruitment process was continued till the end of February. At the beginning of the recruitment process it was difficult to mobilize people because it was just before Christmas. We continued the recruitment process from January to February as the reply rate was quite low. Between December and February ITA contacted about 100-110 potential stakeholders (email based and via telephone).

The following stakeholder groups were contacted, as proposed by the PACITA scenario method document D 6.1 (a detailed list of participants including their institutions is in Appendix A):

- Research and industry (technology developers, technology consulters and marketing, e.g. telemedicine telecare system providers)

- Medical and care personnel (geriatrics, gerontology, care and care educational institutions, NPOs such as the Red Cross)

\section{- Local institutions and politicians}

- Representatives of older adults and relatives who are carers (some of the stakeholders are senior citizens themselves, and so they represent several roles as stakeholder) 


\subsection{Participation}

Some stakeholders cancelled their participation in the last two days before and even on the day of the workshop itself due to important unforeseen appointments or simply because of illness. All in all 26 stakeholders were present on March 26.

\section{Some information about the stakeholders:}

Stakeholders from all groups were present. Interestingly, technology developers were the first to respond to the email invitation. Medical and care personnel were not that responsive, except for a few participants. Two of the medical personnel cancelled their participation at the workshop shortly before the workshop as they had urgent meetings. The same picture was apparent amongst policy makers.

At the beginning we also intended to invite older adults to the workshop, but after a discussion in the consortium we decided to selected representatives for older adults who are engaged in various activities for older adults and are thus capable of representing the interests of older adults during the discussion with other stakeholders.

In general the acquisition of a balanced number of different stakeholder groups was a difficult task. In combination with the methodological framing of the workshop (homogenous groups at the beginning, heterogeneous groups at the end of the workshop) it was difficult to react to "no- shows" especially when more than one person from the same stakeholder group cancelled their attendance. Another important factor is that there are only a limited number of relevant organizations/institutions in the various fields (i.e. research industry, medicine, care). In general only one representative of each institution was delegated to participate at the workshop. It was also not so easy to ascribe dedicated roles to the stakeholders, as some of them had different roles (e.g. being a researcher but also being a caring relative at the same time).

In February, we were also informed by a stakeholder (care provider) that the biggest care congress was being held in Hannover-Germany (from 25.3 - 27.3) on the proposed date (26.03.2014). This was a reason for the absence of some stakeholders from this group. Appendix A shows the stakeholders who participated according their organisation and roles. 


\section{Results-Responses to the scenarios}

The responses to the scenarios are based upon the documentation of the rapporteurs, the notes by the stakeholders and their reactions to the short questionnaire as well as documented responses on post-its in phase 1 and 2. We have only added them up and formulated sentences.

\subsection{Scenario 1: One size fits all}

One size fits all is based on the assumption of shortage of labour in the future, and describes a large-scale governmental initiative using technologies to make people more self-reliant. The local municipalities still provide most of the public support services. However, national standards now determine the home care technologies and services that the local government authorities must provide.

\subsubsection{General response to scenario 1 (phase 1$)^{24}$}

The realism of the scenario was perceived as being ambivalent. The stakeholders stated that on the one hand there was currently a trend towards individual solutions (Scenario 2), but on the other hand there was a trend towards the "One size fits all scenario" being more feasible. An argument against the "One size fits all scenario" was seen in the existing federalism in Austria, which tends to foster different care solutions in the country.

The arguments supporting a "One size fits all scenario" were more prominent, although not till the year 2025. The stakeholder mentioned several times that the care provision needs to be taken care of by the national government. Another aspect which was mentioned by a stakeholder and makes scenario 1 realistic in his opinion is a currently ongoing AAL project called "Modulaar" ${ }^{25}$ funded under the national AAL programme. In this project 50 living quarters in the federal province of Burgenland are equipped with AAL packages tailored according to the needs of the residents. In addition, the stakeholders stressed that the current economic pressure and the urgency of the topic in Austria fosters the "One size fits all scenario", as it would be easier for the government to decide along the "One size fits all" scenario. Concerning the role of technology used in the scenario, it was also perceived as realistic, as technology will play undoubtedly a role in the future.

The aspect of the government-defined standards of the care technologies that have to be used was perceived as an important aspect of the scenario as this would prevent an "uncontrolled growth" of technologies. The fact that the scenario setting provides a secure care basis for all citizens was perceived as desirable and as a positive aspect of scenario 1 . In this way social disparities (income) can be overcome and persons with lower income would have a guaranteed care provision.

A strong argument (barrier) against scenario 1 is the current heterogeneous development of technology, the heterogeneous stakeholders and interests in the care sector and the above-mentioned federalism and pluralism in Austria's political landscape in general.

It was also mentioned that standardised care kits could never cover all the needs and demands of the older adults, as these needs are too heterogeneous (e.g. for dementia). This point counteracts the primary aim of the "One size fits all" scenario to provide a guaranteed care system for everybody.

\subsubsection{Positive responses to scenario 1 (phase 2)}

Standardized packages were perceived positively as they prevent an uncontrolled proliferation of technology. It was argued that the standardisation of care packages could be a cheap solution for the government, as it allows good cost control. Austria's federal states would need to stick to these standards, which would

\footnotetext{
${ }^{24}$ All groups were asked to give their immediate reactions to the three scenarios: positive and negative feedback. Are they realistic? Possible? Desirable? Why/why not? Below are the main reactions to scenario 1

${ }^{25} \mathrm{http}: / /$ www.modulaar.at/index.php?id=32\#.U5BUnShV9LM project homepage
} 
prevent pluralism. Furthermore the government assumes the responsibility for ensuring the provision of care for everybody living in the country.

Care packages as presented in this scenario are a good solution for people who have no special needs, and the technology may help them in everyday tasks.

\subsubsection{Negative responses and concerns related to scenario 1}

The main negative argument against this scenario was that it offers no room for personalisation. What happens with persons who have special needs? Can their demands be covered by the standardized care packages? These care kits are not adequate for persons who have dementia or other special needs for care. In the scenario, surveillance is a primary aspect for providing security for older adults. Aspects like data security and intrusion into privacy were also mentioned in this context.

It will become difficult to ensure that all demands are covered equally. A further important negative aspect is the fact that the users have no say in this scenario. They cannot choose by themselves. Furthermore a potential for the creation of monopolies was seen in this scenario. Who will decide which technological solutions will be included in the care kits. This provides space for corruption and lobbyism.

The stakeholders stressed that in the "One size fits all" scenario there is a potential risk of isolation and the loss of social contacts. Furthermore they mentioned that technology cannot and should not substitute for professional care.

The acceptance of the care kits (technology in general) was stated to be a potential problem, because the care kits are provided top-down by the government, without giving older adults the possibility to choose. As a contradiction to the previously mentioned point, the lack of self-responsibility in this scenario was perceived to be a negative aspect for many older adults, although it could be a positive aspect for people who need special help for making decisions (e.g. dementia).

\subsubsection{Dilemmas in scenario 1}

Care packages aim at a broad care provision, but simultaneously the standardized care packages cannot cover all demands (special needs).

A dilemma between surveillance and more security was identified as being an important aspect in scenario 1 . It was mentioned that the provision of care with these care packages may lead to an incapacitation of the people who use these kits. "Here, this care package is for you. What, you don't want it? This means trouble! Don't be rebellious!" The users emphasise that this scenario involves social pressure to use the care packages, even if the people concerned are not $100 \%$ convinced by it. This could lead to the systematic cheating of the system and reduce the acceptance of the technology. On the contrary people, whose needs are covered well by the care kits are happy with them. Therefore there is a potential risk of disparity between people whose needs are covered well by the care packages and people whose needs are not covered adequately by the care kits. People who do not wish to use the technology will be under pressure. The stakeholders further mentioned that care and assistance for older adults should not be equated with observing older adults. Furthermore the question was raised whether there are alternatives and ways of saying "No, I don't want any support!" (non-technology alternatives).

\subsubsection{Other issues regarding scenario 1}

- It is not very probable that the health care services will collapse by 2025

- The time frame for this scenario is too short to be realistic

- People who need care in the year 2025 have not grown up with technology, which may have an effect on the acceptance of technology

- Too little differentiation in the scenario, with respect to people's special demands

- Federalism in Austria may hinder such a scenario; existing pluralism (federal states);

- A "cross-political" consensus is needed, which will also withstand changes in the political landscape

- The existing heterogeneity of stakeholders/actors may prevent this

- Heterogeneous technology development may prevent this

- Health prevention measures are not addressed sufficiently in the scenario

- The scenario lacks non-technology alternatives 
- Age is only presented as a cost factor, a societal discourse is needed

- packages need to be personalizable

- In the scenario the persons use technology although they don't feel that comfortable with it. This fosters paternalism as regards the citizens/persons who need care.

- With more use of telecare technology, alarm management will play a central role. How to cope with false alarms? Who is responsible if technology fails?

- Technology should not substitute for professional care

- As a solution a mixture of open market and governmental control would be a possible alternative

\subsubsection{Differences of the groups' responses}

This scenario was discussed in Phase 2 in detail by interdisciplinary policy advisors and care professionals/medical personal.

In general there were no big differences in the groups. Two positions can be identified concerning the realism of the scenario. On the one hand there is currently a trend towards individual solutions and on the other hand there is a trend towards regarding the "One size fits all" solution as being more feasible (this argument was more prominent).

In addition, the standardized care-kits were perceived ambivalently by the stakeholders. On the one hand the concept was regarded as positive because care is guaranteed by the government, and on the other hand the problem of not being able to cover all needs with the care kits was raised. The lack of self-determination (i.e. the possibility to choose individually) was another aspect which works against the "One size fits all" scenario.

\subsection{Scenario 2: Freedom of choice}

Freedom of choice is based on a new political system where the incentives for care recipients go directly to the user. This scenario also describes a society where you can buy a great variety of care services on the open market. Everyone in need of care is entitled to incentives and financial support depending on his or her health condition. The local government authority's responsibility is now to ensure the existence of an adequate supply (national standards or higher) of care services for those living and residing there.

\subsubsection{General response to scenario $2^{26}$ (phase 1)}

The scenario "Freedom of choice" was perceived as a realistic scenario for Austria. This is mainly because in Austria there is an equivalent model based on financial incentives, which goes directly to the care recipient. Furthermore the fact that in Austria private and public suppliers of care services already co-exist also make this scenario realistic. The stakeholders also mentioned that currently there is a deregulation trend in Austria. The stakeholders stated that the aspect of having the freedom of choice is desirable. Nevertheless this immediately raises some challenges. Not everybody can decide for themselves what support they need. Furthermore good information and transparency is needed in order to be able to decide on an informed basis. Unlike scenario 1 this scenario offers a person the freedom to decide what he/she wants/needs (under the premise that everybody knows what he needs and what is available). According to the stakeholders, this scenario allows personalized technological solutions, but there is still the risk that social disparities may get greater. The functioning of the system depends very much on the amount of the incentives.

${ }^{26}$ All groups were asked to give their immediate reactions to the three scenarios: positive and negative feedback. Are they realistic? Possible? Desirable? Why/why not? Below are the main reactions to scenario 2. 
The role of the local government authorities and federal states was also seen as realistic (comment: They have to ensure that citizens are provided with services). The stakeholders believe that it is not desirable for the government to withdraw (with the aim of saving money) and for market mechanisms take on political responsibilities, because health and care is not a place for market interests (health care should be non-profit oriented)

This scenario was perceived as a relative easily realizable for the government, because there are already tendencies in this direction.

\subsubsection{Positive responses to scenario 2 (phase 2)}

The stakeholders expressed that in contrary to scenario 1 this scenario allows freedom of choice. Therefore it is a good model for people who can decide by themselves. Furthermore they stressed that an open market and the resulting higher competition between companies would lead to a diversified care technology landscape (more products). This may result in lower prices for the technological devices/systems. The stakeholders further mentioned that the open market could offer better possibilities for coping with special needs (unlike scenario 1). Nevertheless technology has limits when it comes to supporting people with dementia or other physical or mental impairments. Technology cannot substitute for professional care.

\subsubsection{Negative responses and concerns related to scenario 2}

The stakeholders raised concerns about social equity. They stated that this scenario has the potential to create a two tier society, for two reasons. On the one hand they mentioned that financial resources have a major influence on the care provision that can be bought. Consequently people who are better-off could buy better and more adequate/sophisticated solutions. On the other hand the amount of information the individuals have about the available devices/services also has an impact on the decisions they make.

One aspect which was stated as a possible negative point of the scenario is the potential misuse and failures of the financial care incentives, which are a central measure in this scenario. As Austria already has a similar system (incentives), nearly all stakeholders mentioned that it is difficult to control the use of the care incentives.

A main concern about this scenario was the fact that the government withdraws from its responsibility to provide the care. Furthermore the commercialisation of the health care sector was perceived to be problematic.

Another problem was also seen in the aspect that a wider range of available products could also be too much for older adults, especially if appropriate information is lacking (confusion on the market). Furthermore the higher competition on the market could have an effect on the quality of products, encouraging marketing features instead of the functionality of products. Therefore, the stakeholders mentioned that it is very important that the government defines clear standards and quality criteria.

Concerning the technology, the stakeholders mentioned that the use of technology (e.g. technology substituting for personal care) may lead to the isolation of older adults who need care and assistance. Furthermore the use of technology may not be suitable for every nursing case (e.g. dementia or people with motory, visual or auditive impairments).

Another important concern which was raised for this scenario is the high risk of a technology push. Furthermore it is unclear what effects competition between public and private suppliers would have on care provision. The stakeholders mentioned that there is a high risk that the market could dominate the government.

\subsubsection{Dilemmas in scenario 2}

Technological possibilities always also produce new compulsions. The question emerged of whether there will be sanctions if someone refuses to use technology. Therefore it needs to be clarified whether the use of 
technology is compulsory. The tension between surveillance and personal safety was also mentioned as a problematic aspect in this scenario that has to be considered. The stakeholders also raised the question of equity. They saw the potential risk of the disparity between rich and poor becoming greater within such a scenario setting. Another worry mentioned was the problem that technology could lead to a substitution for social contacts.

Problems could emerge due to the paradigm of profit maximization by companies, and the quality of the technologies/services provided may decline. The stakeholders mentioned that an increasing number of products is good because it allows for personalized care arrangements, but on the other hand informed decisions need to be based on good and available information. This means that the market needs to be transparent and information needs to be (made) available for everybody.

The increasing use of technology following the aim of ensuring autonomy may also lead to more isolation, due to the substitution of personal care.

\subsubsection{Other issues regarding scenario 2}

- Need for consulting for individuals to help them with the decisions

- Quality control in open market needs to be taken over by the government

- Information and transparency are important premises for this scenario

- Technological services/devices may lead to obligations

- Aggressive marketing may lead to market distortion

- Professional care personal is still needed

- Health care sector should be non profit; commercialisation of the health care sector is not desirable

- It should be possible to turn off the devices

\subsubsection{Differences in the groups' responses}

This scenario was discussed in phase 2 in detail by R\&D/companies and care research stakeholders.

The main difference here was the fact that the $R \& D$ table saw a great potential for innovation in this scenario, whereas the care research group saw the potential for personalized care arrangements. The R\&D group also mentioned that interoperability, quality control, and good information for individuals are needed. The advertisement for products was also discussed. For businesses, the advertisements will be an important aspect for achieving a good custom bond.

The care research group saw the need for adequate training mechanisms in the use of new IC-technologies. Furthermore they addressed the problems of persons with dementia, who are therefore not capable of deciding by themselves. They also mentioned that this scenario demands high competences on the part of the care recipients. Another aspect which was discussed was the problem of the standardisation of health-related data. Devices which monitor health-related data need a standardised data set in order to be able to compare the measured data. This poses the question "What health related data is good data as standardised data sets?"

\subsection{Scenario 3: Volunteering community}

Volunteering community is based on volunteers as the key resource for the community and for each other. This could include the senior citizens themselves, their relatives, charities, neighbours, school children etc. The local government authority's main role is to mobilize the coordination of the volunteer organizations. The local government authorities are responsible for ensuring that there is a proper healthcare for its inhabitants, including monitoring the quality of the care provided. The local municipalities are required to deliver some health services, to manage licenses for private operators and to mobilize the coordination of the volunteering organizations. 


\subsubsection{General response to scenario $3^{27}$ (Phase 1)}

In general it was perceived positively that social relations (fostering social networks for care $\&$ inclusion of healthy older adults) are of central importance for this scenario. This aspect makes scenario 3 "Volunteering community" desirable. The aspect that healthy older adults are appreciated as a valuable resource, able to contribute their skills to the society was remarked positively. The stakeholders stated that this would be a cost-efficient solution for the government as signs indicate that financial subsidies from the government will be reduced in the future and that the informal care sector will become more important. This aspect also makes the scenario realistic for Austria. Nevertheless, within the time frame of 2025 the scenario faces barriers in Austria, because an implementation of a broad volunteering sector would need a deep change of thinking in the Austrian population. This was based on the argument that the current health care system offers little space for such a model.

The role of technology, helping to coordinate the care services, was seen as a positive aspect of the scenario. Nevertheless the stakeholders stated that the coordination and organisation of care services would be extremely difficult in this scenario. For rural areas the scenario was perceived to be a much more realistic model.

The role of volunteer work in Austria was discussed ambivalently. Stakeholders could not agree whether the volunteer sector in Austria is established well enough to be comparable to the situation as it is in the scenario. The stakeholders further stated that quality assurance and control would be difficult in such a system. The aspect that the government hands all of the responsibility over to the volunteers was perceived as problematic.

Arguments against the possibility of the scenario "Volunteering community" stated that, the volunteering model could not compete due to very strong economic interests. Stakeholders also mentioned the problem of a possible substitution of health care professionals by volunteers.

In the discussions questions of payment and compensation of the volunteer work were also raised. What services could be compared to each other? It was suggested that volunteer work could be allowed as pensionable time.

The stakeholders further stressed that this system could easily overburden the volunteer care workers especially if there is an obligation to do volunteer work. Even today caring relatives are already overburdened by the volunteer work (informal care) they do.

In this scenario, what happens to people who have no relatives? They depend even more on volunteer work. Furthermore the stakeholders posed the question of how reliable such a system could/would be in reality.

\subsubsection{Positive responses to scenario 3 (Phase 2)}

The stakeholders remarked that the focus on volunteer work could reduce the problem of the social isolation of older adults. Therefore the focus on personal care based on volunteer work was seen as positive. The stakeholders stated that this scenario strengthens the community feeling. Healthy older adults participate and have the possibility of doing meaningful work for society.

Government support of bottom-up initiatives was seen as a positive aspect of the scenario.

Making social media easy to use for older adults would help to prevent social isolation in this scenario. Furthermore it was also positively remarked that technology helps to overcome spatial distances, enabling contact to be maintained with relatives or friends.

The stakeholders believe that this scenario would be a cheap alternative for the government as the primary care is done by volunteers and relatives.

\subsubsection{Negative responses and concerns related to scenario 3}

The broad implementation of a model as proposed in scenario 3 was perceived to be very difficult, especially, because a good coordination and organization would be needed. The care provision in scenario 3

\footnotetext{
${ }^{27}$ All groups were asked to give their immediate reactions to the three scenarios: positive and negative feedback. Are they realistic? Possible? Desirable? Why/why not? Below are the main reactions to scenario 3.
} 
was also perceived to be too insecure to guarantee that everyone gets the care he/she needs (dependence on volunteering work). Quality assurance was seen as a big challenge for this scenario.

The aspect that the government hands all of the responsibility over to the volunteers and to the relatives was seen to be negative and could put too much of a burden them. They stressed that healthcare is the responsibility of the government.

The stakeholders criticized that there is no claim for basic care provision in this scenario.

Furthermore the stakeholders expressed the concern that professional care work is taken over by volunteers. This could lead to a substitution of professional work by volunteers.

The stakeholders further stressed that in this scenario older adults without relatives are disadvantaged.

Privacy concerns were another important aspect which was mentioned. The stakeholders argued that in this scenario older adults who need care are in the position of beggars. Persons who are cared by volunteers may feel forced to be thankful for the (unpaid) volunteer work.

\subsubsection{Dilemmas in scenario 3}

A serious issue discussed by the stakeholders for this scenario is the reliability of the system. Volunteer care work without compulsion gives no guarantee that the person in need of care receives the care he/she needs. How can good quality of care based upon volunteer work be provided? A feeling that one must participate may occur in small towns or local government authorities due to social pressure.

The stakeholders mentioned that problems may occur when it comes to an imbalance between "giving and taking". Furthermore a lack of technology affinity may lead to the exclusion/isolation of older adults Privacy concerns were also mentioned, especially if unknown volunteers have access to the private environment.

If care technologies are based upon the surveillance of older adults, privacy and data security need to be considered (including volunteers). Problems also may occur if an older adult has no relatives. This person would be even more dependent on persons he/she may not know.

The following questions emerged during the discussions:

How to cope with situations when a volunteer is refused because of antipathy? Is there a freedom to choose the volunteers? How to cope with situations when someone does not want help or does not want to participate and offer his competences?

\subsubsection{Other issues regarding scenario 3}

- Needs a change in the thinking of the citizens (social innovation)

- Very idealistic and collegial picture of the future

- Technology needs to be user-friendly

- Quality assurance needs to be guaranteed

- Dying and volunteering work

- The interaction between technology and care is not discussed enough in this scenario

- Conceivable as a complementary system

- Financing is still needed

\subsubsection{Differences of responses of the group}

This scenario was discussed in phase 2 in detail by representatives of older adults and caring relatives and by political stakeholders and local institutions.

Both groups had in general the same positive feedback on the scenarios. They mentioned the aspect that a volunteering care community helps to prevent older adults becoming isolated, due to the focus on social mobilization for care. In additional technology was seen as a potential solution to help prevent social isolation (e.g. social media, skype). The "political" stakeholders identified the potential risk that professional care could be replaced by volunteer work. They also mentioned that this model could lead to a broader offer of care services. Both tables mentioned that it is the role of the government to ensure that a good care is available. 


\subsection{Additional remarks to the three scenarios:}

In general the feedback of the stakeholders to the scenarios shows that each scenario seems to have their own specific positive aspects, whereas the negative comments on the scenarios much more permeate all three scenarios. This implies that the negative aspects/comments seem not to be linked directly to the setting of the scenario itself, there seems to be more of a general problem which goes beyond the limits of the scenarios. The bullet points describe the key points of the feedback to the scenarios:

- The negative responses in general outweighed the positive responses

- In part the positive responses also gave rise to negative responses in that the positive aspects of a certain technology also poses negative aspects simultaneously

- Across all three scenarios the concern of the replacement of professional care personnel by technology/volunteer work was mentioned

- the timespan till 2025 was perceived to be too short for the scenarios, because the political and social changes in the scenarios were perceived to be too big to be realistic for the next 11 years

- in general the government was perceived as having the main responsibility to ensure the provision of care services, but also to define standards through top-down regulation (Scenario 1 and Scenario 2) and to assure a good quality of care

- every scenario had realistic elements for Austria (scenario 1 and 2 more than scenario 3)

- federalism in Austria was mentioned repeatedly as a barrier, especially for scenario 1 and 2 (in Austria there is currently a heterogeneous care systems)

- privacy concerns resulting from the use of care technologies were mentioned for all three scenarios

- the consideration of special and personal needs was also repeatedly mentioned

- structures for the technical education of older adults were mentioned as being very important for the implementation of technologies 


\section{Analysis and synthesis of visions and recommendations from Austria}

This chapter presents the results of the phase 3 of the workshop, namely the visions with the corresponding recommendations and choices formulated by the stakeholders. Unlike phase 1 and phase 2 of the workshop, the groups in phase three were reorganised in heterogeneous groups, thus presenting at each table a diverse group of stakeholders, allowing the integration of the views of different stakeholders in the visions and recommendations. The new groups were asked to discuss and propose their own vision about the future care for the elderly, and decide which choices are central for the realization of the vision. The participants formulated 1) visions of the kind of elderly care services the participants want in the future and 2) recommendations and choices needed to achieve these visions.

Phase 3 was divided into two parts. First, all stakeholders at the table were asked to write down their personal vision of care for the elderly in the future. These visions were presented and discussed with the other stakeholders at the table. In the second part of phase two, the stakeholders were asked to reach consensus on one or two visions per table (possibly rewrite them and implement missing aspects etc.) and also to formulate recommendations and choices which are needed in order to make the visions real. In the following section an overview of the visions is presented according to each table and according to the aforementioned two-part phase 3. In the first part all the visions of the participants are presented. In the following part the consensus visions including the recommendations and choices are presented. We have translated the visions from German to English, but otherwise we have not changed the visions, in order to stay "loyal" to the stakeholders' visions. This structuring allows the reader to see how the final visions at each table evolved and on what basis they were formulated. The overview of the visions is followed by the analysis and synthesis of the visions and recommendations, which is based only on the final consensus visions and recommendations of phase 3 .

\subsection{Overview of visions}

\section{Table 1}

\section{Visions generated at the table.}

T1-V1: "Free access to care and assistance and a softening of governmental structures. People who need care and assistance can decide by themselves on the type of care and assistance services they want to make use of."

T1-V2: "I want to be perceived and taken seriously as a human being with my biography, a personality and certain skills. There are competent care personnel and a social society in which older adults who need assistance have a local value. I have a person with whom I am familiar to help me in the organisation and coordination of assistance/care. This person also helps me with my bio-psychological needs (affordable!). The access should be easy. I live in inspirational surroundings that foster thinking, laughing .and exchange. There should be the possibility to take part in things that interest me. Human dignity is important in encounters."

T1-V3: "Provision/supply - Guaranteed services for everyone who is in need of assistance. The implementation of these care services is based on definitions from society (it is not economics that decide). These services should be available, affordable and accessible (guaranteed by the government). Everyone has the freedom to decide on the technology and human assistance as far as possible and is guaranteed support in these decisions (information provision). Enough resources need to be allocated (also for paid work). On the individual level: Person-centred approach, i.e. the values and needs of the "users" are the basis of operations and the benchmark. The changing needs and skills also need to be acknowledged. The supply 
should be broad and alternatives available. Everybody has the same access and there are no disadvantages. It should also be possible to revise decisions concerning the place (where I get the assistance/care) and the kind of assistance a person gets, as well as concerning the person who is in charge of assisting.

Participation is also needed."

\section{Consensus Vision and recommendations}

\section{T1-Common Vision:}

Title: I am here

"Each older adult who is in need of care is perceived and taken seriously as an individual personality with a personal biography, with values and capabilities. The support with care services is therefore individually oriented and access to the services is made easy."

\section{Recommendations:}

- Provision of enough resources for integration and care provision

- New economic attitude and rethinking needed (GDP is not the sole criteria for welfare and growth)

- Individual needs should be acknowledged and recognized (help through technology, social contact and communication, social security, personal safety)

- A public discourse on values and a stronger awareness-increase in politics and the public is needed

- Public agreement is needed that being dependant is not a deficit. Public relations work, and public discourse and awareness-increasing is needed.

- Older adults who are in need of care need to be more present in media and in advertisements

- The joy of living at all ages needs to be increased with new structures

- Creation of a clown. The clown as counterpart to the performance society as a first step and signal. Clown workshops for politicians, manager and decision makers

\section{Table 2}

Visions generated at the table.

T2-V1: "There should be basic services and everybody should be able to decide additionally if he/she wants to stay at home or go to a nursing home. There are new forms of nursing homes in which older adults are not only administered, but can also codetermine. The quality of life is not only a matter of social contacts and health. Creativity and art also need to be considered. Furthermore complementary medicine and not only drugs need to be considered"

T2-V2: "Technical systems are adaptive and interoperable. There are guidelines and norms for the implementation for these systems. Furthermore there is a broad range. Financing is based on two pillars private investments and support in financing if needed. Professional and private services coexist."

T2-V3: "Every retiree gets a present for his retirement for free i.e. a basic AAL-Package. This package contains security devices (smoke detector, automated windows and door closer ...) and health devices (monitoring of health related data, alarm function with alarm buttons). Tablet computers are used to interactively interact with the environment. The user can determine if he/she wants to use this (self determination). When the system is activated the user is connected to a care and a prophylaxis professional. These professionals clarify with the user the degree of assistance that is needed and what preventive measures are suitable."

\section{Consensus Visions and recommendations:}


This group developed 2 separate visions but in the end the stakeholders realised that the second vision is the premise for the first one. The recommendations are for both visions.

Furthermore the visions which were written down by the stakeholders were refined during the presentation of the visions. The vision "Flexible system landscape" was seen as a premise for the "LQA - Life Quality in Old Age", because the LQP - live quality packages need to be flexible and adaptable.

\section{T2- Common Vision 1:}

Title: LQA - Life Quality in old Age

"With the first day of retirement the LQP - Live Quality Package is provided for free. At the time of the selfdetermined activation of the system, an initial consulting takes place in $O L D=$ mental health, artistic creativity etc. Information about what technology is available (AAL) and aids and appliances, social services and health prophylaxis are provided"

\section{T2- Common Vision 2:}

Title: Flexible system landscape

"Technical systems are individually configurable and adaptable. Basic care packages are defined through standards, norms and quality directives. Private and public assistance complete each other. Personal data is the property of the user, who decides what, where and for how long this data is saved."

\section{Recommendations:}

- So called LQA - Live quality agents are in charge of the coordination of the LQP. The LQ-Agents meet regularly to exchange their experiences (LQ-Agents working groups). The work of the LQAgents is monitored. It is also possible to change LQ-Agent. This could be achieved by launching new occupational categories to prevent them being too medical.

- Organizations need to be better connected with each other

- Insurance for monetary care incentives needs to be established. Also, the income needs to be redistributed and the income of men and women needs to be raised, so that everybody has enough resources for everyday life.

- A preparation for ageing is needed i.e. learning to get old. This includes the correct use of technological equipment.

- Words like aged society and state of emergency concerning care need to be dismissed from the vocabulary.

- Ageing must not be seen as a debit

- Reform: Financing of the health care system needs to be taken over by the local government authorities and the government

- Norms, quality standards and basic care packages need to be defined

- Markets stimulation through contracts for the provision of basic care

- A broad discussion about privacy protection and data sovereignty and a commitment to new rules of action are needed

- Institutions and municipalities should perceive each other as partners that enable and fund projects and ideas. The population needs to have a say. Furthermore they should act in a holistic, transcultural and interdisciplinary way.

- More transparency in decision processes and involvement of citizens in decision processes.

Table 3

Visions generated at the table. 
T3-V1: "I wish assisted living with all technical support. Enough resources need to be provided in order to be able to have the freedom and choice of the assistance and care I need and want. There is a variety of assistance possibilities. The contact between young people and older adults is fostered. Older adults are integrated in society and they have the opportunity to participate in social life. Furthermore older adults have a meaningful occupation (e.g. reading stories for children)"

T3-V2: "When I'm old I will get the help I desire. I feel secure, appreciated and I live self-determined and I am content."

T3-V3: "Society has taken a new position and has detached itself from the natural scientific risc-discourse. In cooperation with employment policies, "carework" has become more appreciated. Because of this, there is no lack of workers to provide care and there are also enough volunteers who want to help. Society agrees to provide more financial resources in order to secure freedom of choice, concerning the services on offer."

T3-V4: "Fitness instead of incapacitation. Older adults should not only be "served". They should also have the possibility to live their potential, for instance by helping and doing meaningful work. They should have the opportunity to participate in volunteer and neighbourly work. Today this is not possible, for hygienic, time and responsibility reasons. Autonomy first, then exaggerated security measures."

T3-V5: "Volunteers and neighbourly help are important. Self-determination, health care proxy and an ordinance for eventualities are needed. There needs to be enough time to deal with such aspects."

\section{Consensus Vision and recommendations:}

\section{T3-Common Vision 1:}

Title: I want to remain a human being

"Every person receives tailor-made assistance, if possible in familiar surroundings. The autonomy and dignity of the person is in the forefront."

\section{Recommendations:}

- Enough resources need to be allocated (personnel, financial, living spaces). Financial assistance is provided.

- Legal framework conditions need to be established / changed, concerning telemedicine, accountability, provision of services etc.

- Care sector should not only be made visible as a cost factor. There is a need to display the added value of care and assistance. Non-medical occupations need to gain more attention.

- Care activity needs to be more highly rated and appreciated (financial, social appreciation). Care related work needs to be upgraded.

- Alternative and age-based forms of living need to be fostered.

- Neighbourly help and volunteering work need to be promoted

- Intergenerational projects need to be fostered.

- The hospital character of nursing homes needs to be addressed

- A high diversity of assistance and individual technical support is needed. Technical devices have a high quality and the market is regulated by the government.

- Assistance in self-organisation as long as possible.

- The burden on relatives need to be relieved.

\section{Table 4}

\section{Visions generated at the table.}


T4-V1: "Product and service development is based upon given standards and norms. Basic care is provided by public structures (cost rates). A system for the quality control for products and services is established. The implementation of developed systems is eased and educational systems for personnel in training have been established. Adequate infrastructure is available and volunteers and non-professionals are a part of the care system."

T4-V2: "Mindfulness - Economical - Effective - the modular care system 2025. As a part of the modular care system, standardized modules, quality assured through research, are provided. This system is inexpensive for the government and offers enough leeway for local government authorities and recipients. Care modules are interdisciplinary in composition and respect the lives of people in need."

T4-V3: "People in need of care receive cash benefits, allowances in kind and aids, which cover their care needs comprehensively. These services are completely funded."

T4-V4: "Provision is ensured for everybody. Quality standards are maintained. People in need of care have the freedom of action and the freedom to decide. Technical systems are considered, if they promise an improvement of care and assistance. Volunteers are included in the care system."

\section{Consensus Visions and recommendations:}

The following two visions were defined as a complementary package. Each of them addresses a different level of action.

\section{T4-Common Vision 1:}

Title: Support and funding level; "Mindfulness - Economical - Effective"

"A basic care provision is secured for everybody. People in need of care have freedom of action and freedom to decide. The dignity of people who need care is respected."

\section{Recommendations:}

- A legal framework needs to be created. The right to get care in old age.

- The care system needs to be modular

- Tax cheaters should be subject to a high penalty and the fines should be invested in the care system. The financial transaction tax is earmarked for social programmes.

- A care cluster needs to be defined consisting of three aspects, people, rights and ethics

- A wide range of available devices and services to choose from. Furthermore, consulting institutions are established to assist the people in need of care (what is available, how to finance it, assist in decisions etc.).

- Educational and training programmes need to be established (technology in terms of care and assistance)

- New occupational fields need to be developed in the nursing field, and there will also be a need, as the use of technology in care will call for new occupational fields.

- Information transmission and collection and privacy policy need to be considered.

\section{T4-Common Vision 2:}

Title: Technical and regulatory level; "Checked - Full coverage - Quality assured"

"Standards are developed based upon interdisciplinary research. Care and assistance are professionalised and is widely available in rural and urban areas."

\section{Recommendations:}


- Norms and standards need to be defined by national and/or European institutions

- Infrastructural measures for telecommunication are the responsibility of national entities and need to be implemented, and the financing needs to be clarified e.g. through 50 to 100 year bonds with the ECB

- Interdisciplinary and ethical standards need to be developed by national entities.

- Information and health centres need to be easily accessible in rural areas

- Higher professionalism through special educational and training programmes

- Consideration of privacy policy issues

\section{Table 5}

\section{Visions generated at the table.}

T5-V1: "Self-determined, autonomous support and care tailored to different levels of requirements, regardless of the economic situation of the person who is in need of care. Basic agreement that old age is of value in society! The financing needs to be secured."

T5-V2: "The care provided is oriented along needs and freedom of choice. It is guaranteed that the care and assistance needed is also provided. Certain quality and quantity criteria need to be considered. Support through technology should be based upon free will and be adapted to my personal situation. haptics, usability, access, deletion of data, privacy, support and maintenance are aspects which need to be taken into account, when technology is used."

T5-V3: "Thesis: Care and support needs begin at "break points" of life. Problem: technical (AAL) support cannot be "powered up" spontaneously. Vision: Beginning at "discharge management" a chain of actions is triggered which coordinates and performs the necessary changes and actions."

T5-V4: "Nationwide interdisciplinary focus groups develop scenarios for a 5-year period for their region (see model healthy community). Caregiver, caring relatives, people in need of care, technology professionals, older adults who do not need care, volunteers, social service providers, present their findings to policy-makers."

\section{Consensus Visions and recommendations:}

\section{T5-Common Vision 1:}

Title: Base-oriented, dynamic social policy (Grassroot Project)

"Establishment of nationwide regionally based focus groups for the development of sustainable structures along the value chain involving all players, stakeholders (including elderly people who do not need care and assistance), for the development of demand-and solution-oriented services. Politics/government uses the results and generates binding 5 year plans with funding security, based on the findings from the focus groups."

\section{Recommendations:}

- A political consensus is needed and the financing must be guaranteed.

- Privacy policy, data rights in the system, deletion of data, usability and haptics are important aspects which need to be considered in the use of technology for care.

- There needs to be a liability for the implementation.

- Support and maintenance need to be ensured if technology is used.

- First of all a model project needs to be implemented and then the focus groups should be implemented nationwide (evaluation of the model project)

- Contracts need to be easily understandable. 
- The results should be present in the media

- Implementation of the structure proposals for a 5 year period.

- In the future, care and assistance is considered as a positive economic factor that creates meaningful jobs. Politics support new centres of excellence, promote research, etc.

\section{T5- Common Vision 2:}

Title: Good ageing between human and robot

"Free choice between personal care \& assistance and technological support, without a contract. Respectful appreciative dealing with the elderly, with and without technological support. "Age is precious and not just expensive!"”

\section{Recommendations:}

- Launch of campaigns to deal with the taboo topic of care and ways to deal with it. This could be manifested in the ethics class.

- Establishment of a lobby for people who are in need of care

- Opportunities to try different things in e.g. R \& D centres, living labs, demonstrations, Rent a Robot

- Making best practice visible (word of mouth advertising)

- Training of stakeholders

- Good and tested range of products for all services in the chosen environment

- Consultants and coaches help with decisions.

- Individual packages will be developed for those who need them, and are constantly adjusted to personal situations

- Determination free of charge in competence centres is possible. The competence centres also demonstrate different ways of care and assistance.

- Fulfilling quality of life in old age is flexible and malleable

\section{Table 6}

\section{Visions generated at the table.}

T6-V1: "Self-determination and the freedom of choice are central. Technology is used as a support, but there is no "duty" to use technology. Technologies are multidisciplinary developments involving the participation of the end user."

T6-V2: "Strong personal contacts are fostered (humans are social beings). The function of technologies is to ease everyday life (make aware of life and to make happy - not to monitor). Freedom, the personality and privacy have to be respected. The deletion of data needs to be considered. Control mechanisms also need to be established."

T6-V3: "Everybody needs to be offered personal relationships combined with the freedom of choice. Technical support is tailored to individual needs, independently of the economic circumstances of the persons in need of care. Furthermore a broad social discourse about "ageing well, care, assistance, technology" needs to be initiated and encouraged. Ageing can/must be learned and ageing needs to be learned by individuals."

\section{Consensus Visions and recommendations:}

\section{T6-Common Vision 1:}

Title: Self-determined with technology as "friend" 
"Every person who needs care and assistance needs to have freedom of choice. Technology should make life easier and help in everyday life, but not only monitoring (i.e. constant monitoring). Technology can be a motor to bring people together (chats)."

\section{Recommendations:}

- Training in the use of technology should be subsidised

- More technology is needed for prophylaxis, not only technologies with an alarm function

- It should be possible to delete data and less data should be saved

- Technology needs to be user-friendly and cover all needs (i.e. if cognitive impairments exist); endusers should be involved in the development process

- A legal framework for privacy needs to be created

- There should be in/out options, without sanctions

- The interface between technology and health needs to be established

- Intergenerational social discourse on the topic "age well" needs to be initiated and encouraged (for both visions)

\section{T6- Common Vision 2:}

Title: People remain social beings in old age

"Older adults live socially networked in relationships. The exchange / networking between all generations exists and is possible."

\section{Recommendations:}

- Intergenerational social discourse on the topic "age well" needs to be initiated and promoted

- A platform for intergenerational exchange needs to be established

- Strong personal contacts need to be ensured (if wanted) e.g. with doctors, nurses, family members, relatives, volunteers, but technology should not replace professionals

- A balance between the support for individually selected living arrangements in old age (fostering "at home") and the supporting of individual reflection on the type of housing that is suitable in old age ("How do I want to live in 10 years?"), is needed

- Financial resources for the facilitation / development of the social discourse on ageing are needed

- Training in the use of technology should be (financially) subsidised

- A constant and competent evaluation is needed

- Doctors and medical protection are mobile. Caregivers are integrated, international and incorporate volunteers and relatives

- Care personnel need to be motivated and monitored 


\section{Clustering of the consensus visions according to their main topic}

In this chapter we have tried to cluster the visions according to their primary thematic focus. Although they in part cover a number of thematic aspects, we have assigned them to the most prominent topics which they implement. In addition, the synthesis of the recommendations allows a more systematic view of the visions and recommendations for the upcoming trans European comparison.

\subsection{Recognition and acknowledgement of individual needs}

T1-Common Vision: I am here

"Each older adult in need of care is perceived and taken seriously as an individual personality with a personal biography, with values and capabilities. Support with care services is therefore individually oriented and access to the services is made easy."

\subsection{Self-determination, autonomy and freedom of choice}

T3-Common Vision 1: I want to remain a human being

"Every person gets tailored assistance, if possible in familiar surroundings. The autonomy and dignity of the person is in the forefront."

T2-Common Vision 1: LQA - Live Quality in Old Age

"On the first day of retirement the LQP - Live Quality Package is provided free of charge. At the time of the self-determined activation of the system, an initial consultation takes place in OLD = mental health, artistic creativity etc. Information about technological services ( $A A L)$ and aids and appliances, social services and health prophylaxis are provided"

T6-Common Vision 1: Self-determined with technology as "friend"

"Every person who needs care and assistance needs to have the freedom of choice. Technology should make life easier and help in everyday life, but not only monitoring (i.e. constant monitoring). Technology can be a motor to bring people together (chats)."

T5-Common Vision 2: Good ageing between humans and robots

"Free choice between personal care \& assistance and technological support, without a contract. Respectful appreciative dealing with the elderly, with and without technological support. "Age is precious and not just expensive!"”

\subsection{Guaranteed basic care provision}

T4-Common Vision 1: Support and funding level; "Mindfulness - Economical - Effective"

"Basic care provision is secured for everybody. People in need of care have the freedom of action and the freedom to decide. The dignity of people who need care is respected."

\subsection{Participation and inclusion}

T6-Common Vision 2: People remain social beings in old age 
"Older adults live socially networked in relationships. The exchange / networking between all generations exists and is possible."

T5-Common Vision 1: Base oriented, dynamic social policy (Grassroots Project)

"Establishment of nationwide regionally-based focus groups for the development of sustainable structures along the value chain, involving all players, stakeholders (including elderly people who do not need care and assistance), for the development of demand-and solution-oriented services. Politics/government uses the results and generates binding 5 year plans with funding security based on the findings from the focus groups."

\subsection{Technology as support}

T2-Common Vision 2: Flexible system landscape

"Technical systems are individual configurable and adaptable. Basic care packages are defined through standards, norms and quality directives. Private and public subsidies complete each other. Personal data is the property of the user, who decides what, where and for how long this data is saved."

\subsection{Quality assurance}

T4-Common Vision 2: Technical and regulatory level; "Checked - Full coverage - Quality assured"

"Standards are developed based upon interdisciplinary research. Care and assistance is professionalised and it is widely available in rural and urban areas." 


\section{Synthesis of recommendations \& visions in the national policy context}

Stakeholders considered people's autonomy and dignity above all. Dignity was mentioned by stakeholders as a precondition for guaranteeing a good care provision. Ageing can/must be learned and ageing needs to be learned by individuals. Dignity needs to be respected (Table 6 Vision 3). In the recommendations of the care reform working group (CRW) ${ }^{28}$ dignity as a main value for the care system is not present in this explicit form. In the governmental plan for elderly persons, ${ }^{29}$ dignity plays a central role. A dignified interaction with older people in all areas of the healthcare and social system is demanded.

The results of the PACITA Workshop imply that the 35 recommendations suggested by the reform working group (CRW) should be broadened. In recommendation 11, CRW suggests early diagnosis for persons suffering from dementia, in order to implement early therapeutic measures. Stakeholders at the PACITA workshop ask for an early identification for the need for care in a much broader view.

Stakeholders emphasize the importance of a holistic and interdisciplinary collaboration in the planning of care provision (Table 5 Vision 4). They therefore suggest "Nationwide interdisciplinary focus groups develop scenarios for a 5-year period for their region (see model healthy community). Caregivers, caring relatives, people in need of care, technology professionals, older adults who do not need care, volunteers, social service providers, should present their findings to policy-makers." These focus groups should provide an insight into needs at local level. The early identification of individual needs in different stages of life can contribute to the preparation for the process of ageing ("ageing well" proposed in Vision 3 of table 6).

Overall, the dignity of people needs to be respected and taken into account. The aspect of individual needs was one of the most important aspects discussed during the scenario workshop. The following recommendation exemplifies this (T1-Common vision): "Individual needs should be acknowledged and recognized (help through technology, social contact and communication, social security, personal safety). The stakeholders emphasize the need for the improvement of case management. Furthermore older adults and the care persons should have the opportunity to participate in the identification of care needs. In Austria a medical report after a doctor's visit is the main basis for the decision on care support. CRW-report emphasizes the need for a much more interdisciplinary and coordinated case management (M5, CRW-report, p. 7). Stakeholders demand, in line with M5 in the CRW report, care that is based on needs (T5-V2, T5-V3, T6-V3) and a more individual case management instead of the current system that is based on the reason for the need.

Early identification of care needs is emphasized by the CRW experts (M11, CRW-report, p. 9) and is considered by stakeholders in the PACITA workshop as a dual process (T2-Common vision 2-

Recommendations). Not only is the care system responsible for the early identification, the whole of society also needs a preparation for ageing i.e. learning to get old. This includes training in the use of technological equipment. Education and training on new technical products is also required for the care personnel, according to the stakeholders (T4-Vision 2 and T4- Common Vision 1 and 2 and M9, CRW-report, p. 8) Stakeholders suggest the initiation of a promoted broad social discourse about "ageing well, care, assistance, technology" needs. Ageing can/must be learned and ageing needs to be learned by individuals" (T6-V3), which agrees with M20 in the CRW-report for a broad social discourse.

In the CRW report, experts focus on the awareness building of children and young people who provide care for their parents (M 20, CRW-report, p. 13). The stakeholders in the PACITA-Workshop focus on a broader view (T1-Common vision-recommendations): "A public discourse on values and a stronger increase of awareness-amongst politicians and the public is needed to achieve a public consensus so that every older adult who is need of care is taken seriously and provided with easy access to the services in terms of the individual's dignity and personal biography. " Stakeholders emphasize generally the need to deal with the taboo topic of ageing (T5-Common Vision2: "Age is precious and not just expensive!"). In the "Ageing and

\footnotetext{
${ }^{28} \mathrm{https}: / /$ www.bmask.gv.at/cms/site/attachments/9/7/0/CH2081/CMS1356078635988/empfehlungen der reformarbeitsgruppe pflege.pdf

${ }^{29} \mathrm{http}: / /$ www.sozialministerium.at/cms/site/attachments/4/7/6/CH2229/CMS1218014040042/bundesseniorenplan_kompl.pdf
} 
future - Governmental plan for elderly persons" ${ }^{30}$ the aspect of awareness development was also mentioned as a field of action. A first step in this direction, aimed at transforming the existing stereotypes of "being old", is the documentary film "Und a jeds Leben is anders" ("And every single life is different"). The central message of this movie is that being old is not just an economic aspect and something that is a burden. In this context, the stakeholders at the PACITA workshop stressed that care recipients should not be (socially/politically) perceived as ill but they should receive the assistance and care they need. In other words, a person who is in a situation where he/she needs care or assistance should not automatically be perceived or classified as ill.

The PACITA stakeholders recommend that "new occupational fields need to be developed in the care sector, and there also will be a need for them, as the use of technology in care will call for new occupational fields." (T4 Common Vision 1). This aspect is also discussed and recommended in a similar way in the Ageing and future - Governmental plan for elderly persons. This proposes new "intermediary" forms of care and assistance located between stationary care and mobile care.

Stakeholders also emphasize the need for the self-organisation and services provided by relatives to be given professional assistance in order to relieve the burden on relatives and guarantee autonomy and dignity (T3Common vision 1-recommendations). The CRW report includes both the need for information for relatives and the relief of relatives (M5, CRW-report, p. 7 and M18 and 19, p. 12). The creation of nationwide information platforms both for care recipients and for the relatives is also recommended in the Ageing and future - Governmental plan for elderly persons.

Quality management and the need for national and European norms and standards based upon interdisciplinary research is emphasized by the stakeholders several times (e.g. T4-Common Vision 2) and is mentioned as the need for common standards in the CRW-report (M1, 2, 3 and 4, p. 5 \&6). The implementation of the so called National Quality Certificate (NQZ) ${ }^{31}$ is an important initiative, initiated by the Federal Ministry of Labour, Social Affairs and Consumer Protection to ensure and guarantee good quality in nursing homes. This measure has already been implemented and nursing homes can apply for this certificate

\section{The role of technology:}

In the PACITA Stakeholder Workshop the need for social and organizational innovations prior to technological innovations (AAL) was expressed to be important. AAL technologies need to be user friendly and respect privacy related issues. The CRW only focuses on the autonomous living aspect of AAL technologies, neglecting or not addressing the potential problems which may arise due to their use. The recommendations of the stakeholders address this more comprehensively. For instance training in the use of technology should be financially supported, or users should be involved in the development process of AAL technologies. The stakeholders also recommend that the "interface between technology and health needs to be established" (Table 6 common Vision 1).

The recommendations of the CRW only address the care system as it is and how it should be. In comparison, the recommendations and visions elaborated by the stakeholders are multidimensional policy packages, which address different responsibilities and are long term strategies (at least 50-100 years). One example of these multidimensional policy packages is the following vision (T4 common vision 1 and 2):

"A basic care provision is guaranteed for everybody. People in need of care have freedom of action and freedom to decide. The dignity of people who need care is respected."

\footnotetext{
${ }^{30} \mathrm{http} / / /$ www.sozialministerium.at/cms/site/attachments/4/7/6/CH2229/CMS1218014040042/bundesseniorenplan_kompl.pdf

${ }^{31} \mathrm{http}: / /$ www.nqz-austria.at/
} 
And

"Standards are developed based upon interdisciplinary research. Care and assistance is professionalised and is widely available in rural and urban areas."

Stakeholders mentioned the following example recommendations to achieve these targets:

- A care cluster needs to be defined consisting of the three aspects, people, rights and ethics

- A wide range of devices and services to choose from. In addition, consulting institutions are established to assist the people in need of care (what is available, how to finance it, help in decisions etc.).

- Educational and training programmes need to be established (technology in the field of care and assistance)

- New occupational fields need to be developed in the nursing sector, and there will also be a need for them as the use of technology in care will call for new occupational fields. Information transmission and collection and privacy policies need to be considered

- Information and health centres need to be easily accessible in rural areas

In addition, stakeholders emphasize the need for interdisciplinary ethical standards to be developed by national entities taking into account the European context.

In the following section we present the synthesized recommendations generated during the PACITAStakeholder workshop in Austria. They can be summed up in the following nine categories:

\subsection{Recommendations}

\subsubsection{Assurance and recognition of individual needs}

Basically the stakeholders recommended that the individual needs are of central importance in the provision of care in the future. Every person has their own history and different skills. This means that the individual needs (i.e. technical, social and personal needs, as well as the guarantee of personal safety) differ according to personal history and therefore need to be acknowledged and recognized by the relevant actors. This can be achieved through a modular care system that is highly adaptable to the individual needs. They can also be adapted to the changing needs of the individuals. Furthermore the stakeholders mentioned the importance of the involvement of end users in the R\&D process (user-centred approach). A proposal for a possible way of evaluating individual needs was a "competence centre" in which personal needs can be identified. In the competence centres different ways of care and assistance are also demonstrated.

\subsubsection{Self-determination, autonomy and freedom of choice}

The stakeholders recommended that a high diversity of solutions is needed. The diversity also covers nontechnological solutions so that alternatives are available to choose from. Furthermore it should be possible to try different technological solutions before deciding which one best suits the personal needs (living labs, $\mathrm{R} \& \mathrm{D}$ centres, demonstrations etc.). It should also be possible to refuse technological assistance without having to fear sanctions. In this context it is also important that contracts are written in an understandable manner. Everybody should have the possibility and opportunity to choose and determine by themselves the assistance and care that they wants. Concerning the living arrangements in old age, the stakeholders recommended that there is a need for support in decisions making for persons to help them ("How do I want to live in 10 years?"). 


\subsubsection{Guaranteed basic care provision}

In the reflection process of Phase 1 and Phase 2 the stakeholders also mentioned that health care provision is the responsibility of the government and that a good financial basis is needed. This aspect was also mentioned several times in phase 3 . The stakeholders recommended that enough resources (personnel, financial, living spaces) need to be allocated in order to guarantee a basic care provision. The financing of the health care system has to be taken over by the local government authorities and the government, and there is therefore a need for reform and for a new economic attitude ("GDP is not the sole criteria for welfare and growth"). Income also needs to be redistributed and the income of men and women need to be increased so that everybody has enough resources for everyday life. The stakeholders further stressed that a legal framework is needed which guarantees that everybody has the right to receive the care he/she needs. As a basis for the stable financing structure, a broad cross-party political consensus is needed. In addition organisations need to be better connected with each other.

\subsubsection{Participation and inclusion}

Stakeholders stressed that it is important to include older adults in social life (inclusion) and that involvement in R\&D processes is needed ("end-users should be involved in the development process"). It is only through participation that the real user needs can be determined and that technology can be developed specifically. Citizens also need to have a say on the framework definition of the future care. The encouragement of intergenerational projects was seen as a promising way to achieve the social inclusion of older adults and to promote intergenerational exchange. Furthermore the inclusion of older adults in society could be achieved by better and stronger neighbourly and volunteering work. Another way to foster inclusion and social participation of older adults proposed by the stakeholders is to give them meaningful work and a function in society. This was also seen as a way to increase the joy and quality of living, which was identified as being of central importance for the daily life of older adults. Furthermore the stakeholders mentioned that strong personal contacts need to be possible to e.g. doctors, relatives, volunteers, but technology should not start to replace this. The stakeholders further mentioned that it is necessary to relieve the burden on relatives as much as possible.

\subsubsection{Framework conditions (legal, social, economic, norms \& standards)}

Many of the stakeholders' recommendations for the provision of care in the future addressed the need for adequate framework conditions. The stakeholders called for the establishment of legal framework conditions concerning telemedicine, accountability, provision of services etc. In addition the government is responsible for the regulatory work (i.e. norms and standards need to be defined top down). Furthermore, the stakeholders stressed that it is important that institutions and municipalities should perceive each other as partners that enable and fund projects and ideas. More transparency in decision-making processes and the involvement of citizens in these processes need to be fostered. In addition, the institutions and local government authorities should act in a holistic, transcultural and interdisciplinary way. A care cluster consisting of the three aspects, people, rights and ethics needs to be established.

If the market is involved in the care business, the government has the obligation to regulate the market. The strong influence of economic values needs to be weakened, in order to prevent the sole reign of economic interests.

The future provision of care and assistance is considered as a positive economic factor that creates meaningful jobs. Politics support new centres of excellence, promote research, and support the implementation of model projects, which are a first step to nationwide implementation (evaluation of the model project also needed). Furthermore, care personnel needs to be motivated and their work needs to be controlled. The care activity needs to be higher rated and appreciated (financial, social appreciation). In the future care system, doctors and medical protection are mobile and caregivers are integrated and international, with volunteers and relatives also involved. 
The stakeholders also came up with a concrete recommendation for the financing of the health care system. Tax cheaters should pay high penalties and the fines should be invested in the care system. In addition, the financial transaction tax should be earmarked for the financing of social programmes. Another proposal for the financing of the future care was a care insurance.

An infrastructural framework condition (broadband connection) was also proposed by the stakeholders. For this reason there is a national obligation to guarantee a good infrastructure, especially in rural areas.

\subsubsection{Need for the education of personnel working for and with older adults, and education for older adults}

Recommendations on education and the provision of information were also mentioned by the stakeholders and are seen as an important factor in future (health) care provision. Training courses and educational programmes for older adults, as well as for care personnel, are needed and they also should be subsidised. These programmes are also likely to achieve a higher professionalism of the care personnel.

The stakeholders recommended the implementation of consultants and coaches to assist in the decisionmaking process and help with the use of new technologies. They also stressed that new occupational fields need to be developed in the nursing sector, and there also will be a need for them, as the use of technology in care will call for new occupational fields. The stakeholders also suggested that preparation should be provided for the process of ageing (i.e. learning to get old). Assistance in self-organization as long as possible is needed. So called consulting institutions could be established to assist the people in need of care (what is available, how to finance it, assistance in decisions etc.). Information should be easily accessible, especially in rural areas. Additionally, a continuous and competent evaluation of the ongoing processes is needed.

\subsubsection{Changing the public perception of older adults}

The stakeholders also mentioned that a broad public discourse, awareness increasing and public relations work on ageing is needed in society and in the political sector. This could be done by a higher presence of older adults in media and advertisements. "Being dependant is not automatically a deficit" was one central quotation in this context. The care sector should not only be made visible as a cost factor. There is a need to display the added value of care and assistance. The work of non-medical occupations also needs to be upgraded. Expressions like "aging society" and "state of emergency in the field of care" need to be eliminated from the vocabulary, because this is contributing to the negative perception of age and care. The stakeholders proposed for instance the establishment of a platform for intergenerational exchange. This would promote intergenerational social discourse on the topic of "aging well". Furthermore the stakeholders suggested the establishment of campaigns to deal with the taboo topic of care and the ways to deal with it. The establishment of a lobby for older adults was also proposed. This could be manifested in the ethics class. More financial resources are needed for the implementation of this.

\subsubsection{Use of technology and privacy issue}

Privacy issues concerning the use of technology for care were also mentioned by the stakeholders. They stressed the need for a legal framework that addresses the privacy issues resulting from the use of care technologies. They therefore demand a broad discussion about privacy protection and data sovereignty. The users should be and remain the owners of their personal health data with the option of deleting data if they want (not too much data should be saved).

\subsubsection{Technology}

Concerning technologies, the stakeholders mentioned that a good and tested range of products in the chosen living environment needs to be provided. Technologies should have high usability (user friendly), good haptics and they need to cover all the person's needs (e.g. if they suffer from cognitive impairments). The stakeholders further recommended that more prophylaxis technologies are needed (not only technologies 
with an alarm function). Additionally the stakeholders stressed that support and maintenance needs to be ensured if technology is used. Furthermore best practices must be made visible (e.g. through word-of-mouth advertising). An important remark made by the stakeholders was the need to create and establish an interface between technology and health. 


\section{Summary and concluding remarks}

\subsubsection{A short overview of the general reactions to the scenarios "One size fits all", "Freedom of choice" and "Volunteering community" are:}

- Across all three scenarios, mention was made of the concern that professional care personnel could be replaced by technology/volunteering work.

- The timespan up to 2025 was perceived to be too short for the scenarios, because the political and social changes in the scenarios were perceived to be too big to be realistic for the next 11 years.

- In general the government was perceived to have the main responsibility for the provision of care services, and for defining standards through top down regulation (Scenario 1 and Scenario 2) and for assuring a good quality of care

- Every scenario was perceived to have realistic elements for Austria (scenario 1 and 2 more than scenario 3, because the latter presupposed the social innovation).

- Austrian federalism was mentioned repeatedly as a barrier especially for scenario 1 and 2 (in Austria there is currently a heterogeneous care system).

- Privacy concerns resulting from the use of care technologies were mentioned for all three scenarios.

- Structures for the technical education of older adults were indicated to be very important for the implementation of technologies.

\subsubsection{Dilemmas in scenario 1}

Special needs cannot be covered by care packages A dilemma between surveillance and more security was identified

There is a potential for social pressure: "Here, this care package is for you. What, you don't want it? This means trouble! Don't be rebellious!"

This could lead to systematic cheating of the systems and lower the acceptance of the technology. People who do not wish to use technologies will be under pressure.

The stakeholders also mentioned that the care and assistance for older adults should not be equated with observing older adults. The question was also raised whether there are alternatives and ways of saying 'No, I don't want any support!' (non-technology alternatives).

\subsubsection{Dilemmas in scenario 2}

The tension between surveillance and personal safety

Potential risk that the disparity between rich and poor may become greater within such a scenario. Technology could replace social contacts. The increasing use of technology with the aim of ensuring autonomy may also lead to more isolation.

The question arose whether there will be sanctions if someone refuses the use of technology. Problems could emerge due to the aim of companies to maximize profits, and the quality of the technologies/services provided may decline. The stakeholders mentioned that increasing the number of products is good because it allows for personalized care arrangements, but on the other hand informed decisions need to be based on good and available information. This means that the market needs to be transparent and information needs to be (made) available for everybody.

\subsubsection{Dilemmas in scenario 3}

A feeling of compulsion to participate may occur in small towns or villages due to social pressure. A lack of technology affinity may lead to the exclusion/isolation of older adults Privacy concerns were also mentioned, especially if unknown volunteers have access to the private environment. 
Problems also may occur if an older adult has no relatives. This person would be even more dependent on persons he/she may not know.

The following questions emerged during the discussions:

Is this system reliable?

How would the quality be controlled?

How to cope with situations when a volunteer is refused because of antipathy? Is there a freedom of choice of the volunteers? How to cope with situations when someone does not want help or does not want to participate and to offer his skills?

\subsubsection{Putting into national context}

Austria is facing new demographic challenges. According to forecasts, in $203024 \%$ of the Austrian population will be 64 and older. The Austrian health care system is based on a compulsory social insurance system. Public health services and administration are jointly provided by federal, provincial and local authorities. In addition, the provinces are in charge of ensuring hospital care for their inhabitants as well as providing health promotion and prevention services. The local government authorities are in charge of social welfare benefits and services. Due to the diversification of powers and the federal structure of the health care system, there is a need for the coordination of these instances/actors. The central regulatory instrument in this context is "Art. 15a of the Federal Constitutional Act". This agreement is a treaty between the federal government and the nine federal states of Austria, and guarantees the financing, organization and coordination of the health care system on a four year basis.

The care system is "causally focussed", which means that the services are not based upon the needs. The services are based upon the reason for the needs. Thus the same needs resulting from different reasons may be treated differently (e.g. the services provided differ for leisure accidents and for work accidents).

The function of the care system depends very much on informal care (mostly by female family members). In comparison to Scandinavian countries, informal care plays a central role in the Austrian care system (also holds true for other central European countries). ${ }^{32}$ One of the reasons for this is the fact that cash benefits alone are far from sufficient to cover the costs of the care and assistance. ${ }^{33}$

The latest reform efforts in the care sector started in 2011 in the form of a working party comprising the federal government, the federal states and representatives of system partners (stakeholders, Austrian Medical Chamber, Main Association of Austrian Social Insurance Institutions, older adults, service provider, employees, employers).

In mid 2013 they presented their 35 recommendations, proposing reform measures addressing the following aspects $^{34}$ :

- Improvement of the provision of assistance and care

- Caring relatives

- Personnel

- Financing

The 35 recommendations developed by the working party are of central importance for care reform processes. Several aspects proposed in these recommendations can also be found in the results of the PACITA workshop.

A comparison of the stakeholders' visions and recommendations with the set of 35 recommendations shows the following common measures:

- Individual needs should be acknowledged and recognised instead of the current system, which is based on the reason for the needs.

- Early preparation for ageing requires new educational and training approaches

- A broad social debate should be initiated about ageing well, care, assistance and technology

\footnotetext{
${ }^{32}$ http://www.oeksa.at/files/publikationen/broschuereLangzeitpflege.pdf

${ }^{33} \mathrm{http}: / / \mathrm{www}$. politischebildung.com/pdfs/34 nowak.pdf

${ }^{34}$ https://www.bmask.gv.at/cms/site/attachments/9/7/0/CH2081/CMS1356078635988/empfehlungen_der_reformarbeitsgruppe_pflege.pdf
} 
- This debate should also include increasing awareness and providing information for relatives and the ways to relieve the burden on them

- Initiatives and self-organization of relatives/carers and communities should be supported

- Quality should be guaranteed in every case

The stakeholder workshop generated a much broader set of recommendations. In addition to the similar areas of assurance and recognition of individual needs, the need for a legal framework, national and European quality standards, changing the public perception of older adults and the education of personnel working for and with older adults, they also emphasized:

- Self-determination, autonomy and freedom of choice

- Guaranteed basic care provision

- Participation and inclusion

- Use of technology and privacy issues

The results (feedback on the scenarios, visions \& recommendations) of the workshop also show clearly that technology alone is not enough to cope with the challenges of an ageing society. Technology, be it telemedical, telecare or AAL devices in a broader sense, are just one part of the puzzle in solving the challenges of demographic change. The stakeholders agreed upon the aspect that technology for care can only serve as a support and not as a substitution for professional care. People should be given the freedom to choose the support they wish to use. Their skills and needs should also be taken into account, not only in the $\mathrm{R} \& \mathrm{D}$ process of the technologies, but also in the care and assistance sector itself. The purpose of technology as a tool is to...

..."make life easier and help in everyday life, but not only monitor (i.e. constant monitoring).Technology can be a motor to bring people together (chats).

Technical systems should be individually configurable and adaptable. Basic care packages are defined through standards, norms and quality directives. Personal data is the property of the users and they decide what, where and for how long this data is saved."

Throughout the workshop the Austrian government was mentioned repeatedly as being responsible for providing a good standard of care for the citizens. This is a feature of a classical welfare state. When it comes to the development of technologies, the government's responsibility is to set up regulations and define standards to "direct" the R\&D processes and to prevent proliferation. 


\section{Appendix A: List of participants in the scenario workshop}

\begin{tabular}{|c|c|c|}
\hline Name & Organisation & Role \\
\hline Mario Drobics & $\begin{array}{l}\text { AIT - Austrian Institute of } \\
\text { Technology }\end{array}$ & R\&D technology \\
\hline Wolfgang Klöckl & Carewings Software Solutions & Company \\
\hline Laurent Kolly & Zydacron Telecare GmbH & $\begin{array}{l}\text { Company for telecare } \\
\text { solutions }\end{array}$ \\
\hline Wolfgang Zagler & TU - Vienna & R\&D technology \\
\hline Andreas Kumpf & WPU GmbH & $\begin{array}{l}\text { Interdisciplinary } \\
\text { policy advisor }\end{array}$ \\
\hline Ulrike Bechtold & $\begin{array}{l}\text { Institute of Technology } \\
\text { Assessment }\end{array}$ & $\begin{array}{l}\text { Interdisciplinary } \\
\text { policy advisor }\end{array}$ \\
\hline Annette Hexelschneider & $\begin{array}{l}\text { Austrian Interdisciplinary } \\
\text { Platform on Ageing }\end{array}$ & $\begin{array}{l}\text { Interdisciplinary } \\
\text { policy advisor }\end{array}$ \\
\hline Kerstin Zimmermann & $\begin{array}{l}\text { Federal Ministry for Transport, } \\
\text { Innovation and Technology }\end{array}$ & $\begin{array}{l}\text { Local institutions and } \\
\text { politicians }\end{array}$ \\
\hline Erich Ostermeyer & $\begin{array}{l}\text { Ministry of Labour, Social } \\
\text { Affairs and Consumer } \\
\text { Protection }\end{array}$ & $\begin{array}{l}\text { Local institutions and } \\
\text { politicians }\end{array}$ \\
\hline Birgit Meinhard-Schiebel & $\begin{array}{l}\text { Spokeswoman of the Green } \\
\text { senior citizens Vienna; } \\
\text { Representative of the interests } \\
\text { of caring relatives }\end{array}$ & $\begin{array}{l}\text { Local institutions and } \\
\text { politicians }\end{array}$ \\
\hline Cathrine Grigo & $\begin{array}{l}\text { The Austrian Chamber of } \\
\text { Labour }\end{array}$ & $\begin{array}{l}\text { Local institutions and } \\
\text { politicians }\end{array}$ \\
\hline Alexander Eder & $\begin{array}{l}\text { Vienna Social Fund (Fonds } \\
\text { Soziales Wien-FSW); Section } \\
\text { nursing and care }\end{array}$ & $\begin{array}{l}\text { Local institutions and } \\
\text { politicians }\end{array}$ \\
\hline Robert Em & $\begin{array}{l}\text { Vienna social services (Wiener } \\
\text { Sozialdienste - WSD), senior } \\
\text { citizens nursing service, a } \\
\text { limited liability company }\end{array}$ & $\begin{array}{l}\text { Care, service provider } \\
\text { and medical personnel }\end{array}$ \\
\hline Angelika Draxler & Gerontopsychologist & $\begin{array}{l}\text { Care, service provider } \\
\text { and medical personnel }\end{array}$ \\
\hline Karin Mosser & $\begin{array}{l}\text { Vienna hospital association } \\
\text { (Wien KAV), administration } \\
\text { of the Vienna nursing homes }\end{array}$ & $\begin{array}{l}\text { Care, service provider } \\
\text { and medical personnel }\end{array}$ \\
\hline Ingeborg Galli & $\begin{array}{l}\text { Interdisciplinary consulting for } \\
\text { care services }\end{array}$ & $\begin{array}{l}\text { Care, service provider } \\
\text { and medical personnel }\end{array}$ \\
\hline
\end{tabular}




\begin{tabular}{|c|c|c|}
\hline Tanja Stamm & $\begin{array}{l}\text { FH Campus Vienna- } \\
\text { University of Applied Sciences }\end{array}$ & Care research \\
\hline $\begin{array}{l}\text { Claudia Gröschel- } \\
\text { Gregoritsch }\end{array}$ & Red Cross research division & Care research \\
\hline Verena Moser-Siegmeth & $\begin{array}{l}\text { Danube University Krems - } \\
\text { Center for Management in } \\
\text { Healthcare - care research }\end{array}$ & Care research \\
\hline Doris Pfabigan & $\begin{array}{l}\text { UMIT - The Health \& Life } \\
\text { Sciences University }\end{array}$ & Care research \\
\hline Nora Aschacher & Association - "alters.kulturen" & $\begin{array}{l}\text { Older adults, } \\
\text { representative of older } \\
\text { adults, caring relatives } \\
\text { (informal caregiver) }\end{array}$ \\
\hline Günther Fleischmann & Older adult & $\begin{array}{l}\text { Older adults, } \\
\text { representative of older } \\
\text { adults, caring relatives } \\
\text { (informal caregiver) }\end{array}$ \\
\hline Christine Benischke & $\begin{array}{l}\text { Older adult; Organisation of } \\
\text { the master course on } \\
\text { interdisciplinary gerontology } \\
\text { at the University of Graz; } \\
\text { Member of the Active Older } \\
\text { Adults in Graz association, }\end{array}$ & $\begin{array}{l}\text { Older adults, } \\
\text { representative older } \\
\text { adults, caring relatives } \\
\text { (informal caregiver) }\end{array}$ \\
\hline Harald Glatz & $\begin{array}{l}\text { Representative of older adults } \\
\text { (Social Democratic Party of } \\
\text { Austria) }\end{array}$ & $\begin{array}{l}\text { Older adults, } \\
\text { representative of older } \\
\text { adults, caring relatives } \\
\text { (informal caregiver) }\end{array}$ \\
\hline Katharina Fatzi & $\begin{array}{l}\text { Caring relatives (informal } \\
\text { caregiver) }\end{array}$ & $\begin{array}{l}\text { Older adults, } \\
\text { representative older } \\
\text { adults, caring relatives } \\
\text { (informal caregiver) }\end{array}$ \\
\hline Franz Karl & $\begin{array}{l}\text { Representative of older adults } \\
\text { (Austrian People's Party) }\end{array}$ & $\begin{array}{l}\text { Older adults, } \\
\text { representative of older } \\
\text { adults, caring relatives } \\
\text { (informal caregiver) }\end{array}$ \\
\hline
\end{tabular}




\section{Appendix B:Photos}
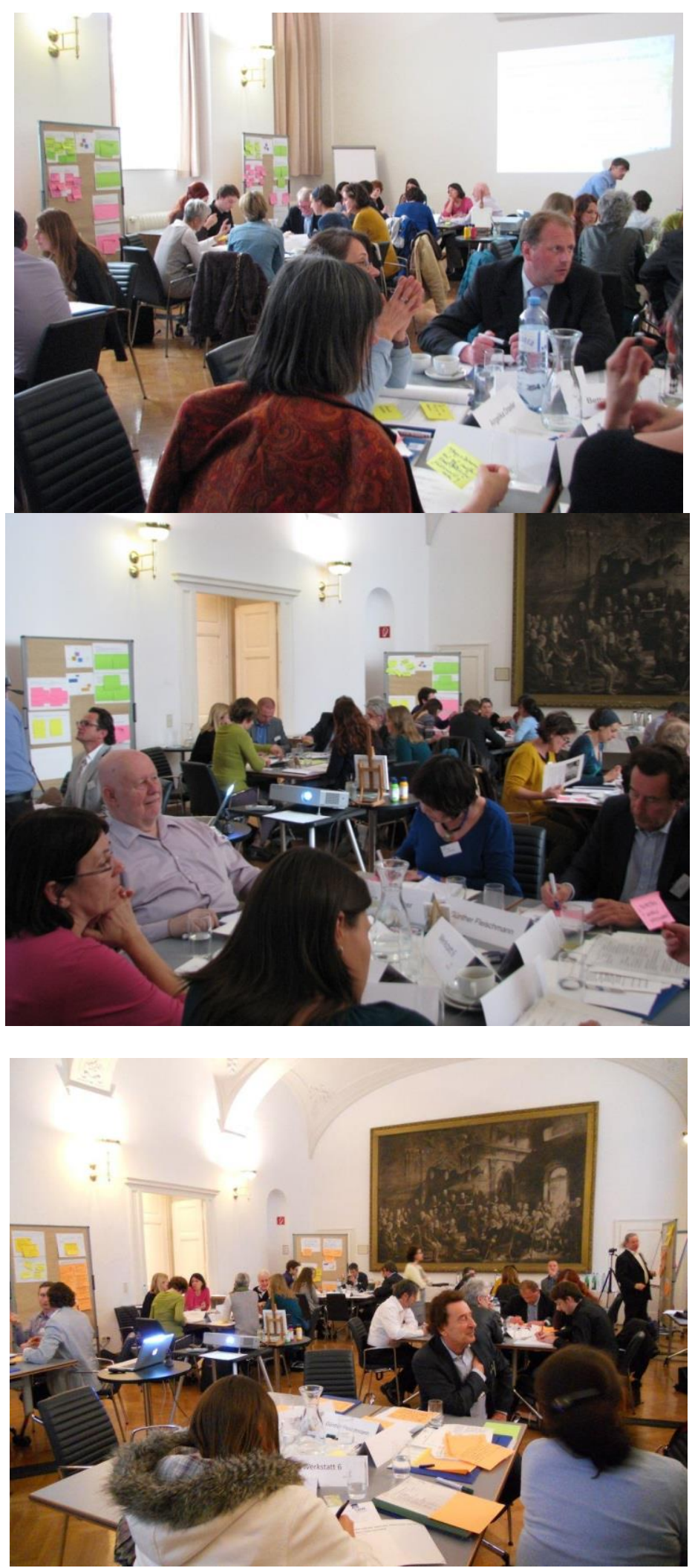